NASA Contractor Report 180888

$$
\begin{aligned}
& \text { LEWIS GAANT } \\
& \text { IN- } 35
\end{aligned}
$$$$
121843
$$

\title{
High Temperature Tensile Testing of Ceramic Composites
}

\author{
(BASA-CE-1808E8) BIGE TEREEATUAE TEASILE \\ TESTIHG OF CEEALIC CCECSIIES Innual Report \\ N8 $8-15 \subseteq \subseteq 6$ \\ (Cleveland state toiv-) \\ $46 \mathrm{~F}$ \\ CSCL 14B \\ $63 / 35 \quad 0121843$
}

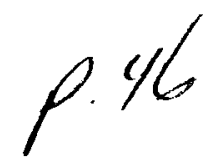

John Z. Gyekenyesi and John H. Hemann

Cleveland State University

Cleveland, Ohio

February 1988

Prepared for

Lewis Research Center

Under Grant NAG3-749

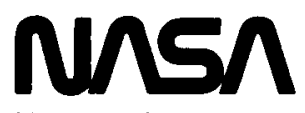

National Aeronautics and

Space Administration 
HIGH TEMPERATURE TENSILE TESTING OF CERAMIC COMPOSITES

\author{
John Z. Gyekenyesi and John H. Hemann \\ Cleveland State University \\ Deparment of Civil Engineering \\ Cleveland, Ohio 44115
}

\begin{abstract}
SUMMARY
The various components of a high temperature tensile testing system are evaluated. The objective is the high temperature tensile testing of Sic fiber reinforced reaction bonded $\mathrm{Si}_{3} \mathrm{~N}_{4}$ specimens at test temperatures up to $1650^{\circ} \mathrm{C}\left(3000^{\circ}\right)$. Testing is to be conducted in inert gases and air. Gripping fixtures, specimen configurations, furnaces, optical strain measuring systems, and temperature measuring techniques are reviewed. Advantages and disadvantages of the various techniques are also noted.
\end{abstract}

\title{
INTRODUCTION
}

Ceramic composites are presently being developed for high temperature use in heat engine and space power system applications. These ceramic composites offer increased toughness over monolithic ceramics as can be seen by the idealized stress-strain curves shown in Fig. 1. The operating temperature range is expected to be up to the limit of available fibers, perhaps eventually to $1650^{\circ} \mathrm{C}\left(3000^{\circ} \mathrm{F}\right)$ or above. Very little mechanical data is available for fiber reinforced ceramic composites at these high temperatures. The proper conduct of such characterization tests requires the development of a tensile testing system in preference to flexural tests. Flexure tests produce maximum stresses only in a small volume near the surface of a specimen while tensile testing produces maximum stresses through the volume. A tensile testing system includes unique gripping, heating, temperature and strain measuring devices which require special considerations. The system also requires an optimized specimen shape.

The purpose of this paper is to review various systems and devices which may be applicable to the high temperature tensile testing of unidirectional fiber reinforced ceramic composites. The tests are to be performed in air to determine their characteristics in an environment which would be similar to that of the 
composite's final application. The testing temperature will be $1650^{\circ} \mathrm{C}\left(3000^{\circ} \mathrm{F}\right)$ which is approximately the use limit of the available silicon based ceramics in an oxidizing atmosphere. Some testing will be performed in an inert atmosphere to eliminate the effects of oxidation.

Until now, very few high temperature tensile tests have been performed on composites in air, and these tests have been limited to a maximum temperature of $1000^{\circ} \mathrm{C}\left(1830^{\circ} \mathrm{F}\right.$ ) (refs. 1-7). The specimens in most of these cases were SiC fiber reinforced glass-ceramic matrix composites which have a lower operating temperature range when used in structural components. our objective is to test Sic fiber reinforced reaction bonded $\mathrm{Si}_{3} \mathrm{~N}_{4}(\mathrm{SiC} / \mathrm{RBSN}$ ) and $\mathrm{SiC}$ fiber reinforced $\mathrm{SiC}$ ( $\mathrm{SiC} / \mathrm{SiC}$ ) composites which can sustain higher

temperatures than the glass-ceramic matrix composites. The various components of the tensile testing system are covered individually. A number of grip designs were evaluated to determine which techniques are most applicable to the high temperature tensile testing of longitudinal fiber reinforced ceramic composites. The specimen size and shape were optimized based on a number of limitations which will be discussed. This is followed by an evaluation of various furnace or high temperature chamber configurations. Finally, a number of strain measuring techniques are described, followed by some recommendations for the total tensile testing system.

\section{GRIPPING FIXTURES}

For high temperature tensile testing, it is desired that the temperature of the grips should be the same as the temperature of the specimen gage section. This condition would minimize the effects of any potential thermal gradients. Testing in an inert atmosphere would allow the use of hot grips since graphite can be utilized for the grip material. On the other hand, testing in the presence of an oxidizing atmosphere and at temperatures greater than $1000^{\circ} \mathrm{C}$ $\left(1830^{\circ} \mathrm{F}\right)$ results in a highly demanding application for hot grips. At high temperatures, the grips may react with the specimen, and they may also oxidize to cause failure when testing in air. For high temperature testing in air, most practical gripping fixtures require some form of cooling. It is, however, still desirable to have the grips as hot as possible to reduce thermal 
gradients within the specimen. This is due to the fact that such thermal gradients induce additional stresses. In addition, unlike metals and monolithic ceramics, the flat specimens of unidirectional fiber reinforced ceramic composites are extremely weak in shear relative to their longitudinal tensile strength. This limits the types of grips which can be utilized.

For room temperature tensile tests, the use of adhesively bonded tabs and serrated grips offers an optimum setup. This technique is actually the standardized method for testing polymer matrix composites. For ceramic composites, this method gives acceptable results but it cannot be applied at high temperatures, due to the lack of an adhesive which offers adequate strength at high temperatures. Serrated grips have been applied to the high temperature tensile testing of silicon carbide fiber reinforced lithium aluminosilicate ( $\mathrm{SiC} / \mathrm{LAS}$ ), but with no success. The serrated grips were applied directly to the surface of the specimen. As a result, the specimen failed under the grips by shredding (ref. 3 ). Another type of gripping fixture uses one or more pins to apply the load to the specimen. The pins are inserted through holes drilled in the specimen. The holes have to be very accurate so that the load from the individual pins is distributed as evenly as possible across the thickness of the specimen. With the use of more than one pin, the alignment of the holes becomes very critical, since it is important to have the load distributed as evenly as possible among the pins. High accuracy of the hole alignment and concentricity are very difficult to achieve in ceramic composite specimens. This is due to the extreme hardness of ceramics and the varying hardness of ceramic composites as the different materials of the matrix and the fibers are encountered during drilling. Some researchers have experimented with pin grips at room temperature (ref. 8) resulting in shear failure near the grips of the specimen as illustrated in Fig. 2. Pin grips have been applied successfully to cross-plied specimens consisting of a $(0 / 90)$ s layup (ref. 8), but it is difficult to derive basic lamina characteristics from these tests. Another compensating technique which has been applied with the use of pin grips is the reduction of the specimen gage section through the width and the thickness. This technique has promoted failure within the specimen gage section, but the results show lower tensile strengths relative to an as fabricated specimen 
(ref. 8). Additional details of specimen configurations are discussed later in this paper.

Friction grips have been applied to the tensile testing of composites quite successfully. This includes room temperature tests (ref. 9) as well as high temperature tests (refs. 1-7). Most of the grips consist of smooth faces with some type of insert such as Sic paper or alumina to protect the specimen. The force can be applied to the grips by pneumatic, hydraulic, or mechanical means. The mechanical technique just uses wedge grips. For testing at high temperatures the material of the grips would most coveniently be a nickel based alloy or silicon carbide. Researchers at General Electric Company have run tensile tests with a grip temperature of $980^{\circ} \mathrm{C}\left(1800^{\circ} \mathrm{F}\right)$ (ref. 7) using a nickelbase alloy as the grip material.

In tests conducted at the Massachusetts Institute of Technology (ref. 3), a single pin was used in conjunction with the friction grips. The pin was used for initially aligning the specimen. During the test, the pin carried only a small portion of the total load (ref. 3). Another technique used for initial alignment of the specimen with friction grips is to lightly load the specimen and allow it to slip slightly within the grips. The grips are then fully loaded and the specimen is ready to be tested. At Southern Research Institute, great care is taken to align the specimen within the grips. At first, the circular specimen is loaded into the upper grips. Next, the gripping fixture is rigidly fixed such that it can be rotated about its axis. As it is rotated, a dial indicator is used to check run-out at the other end of the specimen. Then the lower grip is clamped onto the other end of the specimen. Supported vertically the straightness of the assembly is checked at various points. Once the assembly is within acceptable tolerances, it is loaded into the tensile testing machine. This technique has been applied to the testing of circular ceramic and carbon/carbon composite specimens. With brittle materials, such as ceramics, alignment is extremely critical (ref. 10) in order to minimize unwanted bending stresses.

Another area of concern related to the gripping fixture is the alignment device in the load train of the tensile testing system. A number of alignment devices are available for tensile testing equipment. Most readily available equipment use universal joints at the end of the load train with rigid grips. Universal joints offer relatively low resistance to motion when unloaded but the frictional forces increase 
significantly as the applied load is increased. A more sophisticated technique recently introduced by oak Ridge National Laboratories (ORNL) uses pistons and hydraulic fluid in the alignment device (ref. 11). This is illustrated in Fig. 3. The device consists of eight pistons that are equally spaced in a circle with hydraulic passages connecting their respective cylinders. The pistons support the pull rod and the hydraulic fluid distributes the loads between the pistons such that all bending stresses are nearly eliminated. The grips are part of the alignment device. As a result, the specimen is located very close to the alignment device which maximizes its effectiveness. This system has been shown to produce bending stresses that are less than $0.5 \%$ of the average applied tensile stress (ref. 11).

A different technique utilizes air bearings at the ends of the load train. This system has been applied at Southern Research Institute. The system is basically a ball and socket separated by high pressure air which offers a virtually frictionless connection. A schematic of the system is shown in Fig. 4. Loads due to extraneous crosshead motion are greatly reduced. In addition, there are no rotational constraints (ref. 12). Since the air bearings are located at the ends of the load train, greater precision is required in loading the specinem into the grips.

\section{SPECIMEN CONFIGURATIONS}

In the case of longitudinal fiber reinforced ceramic composites, it is desirable to use a flat straight sided specimen with tabs bonded to the ends. This would result in a specimen with minimal stress concentrations and minimal cost. Unfortunately, as noted before, the tabs cannot be used due to the lack of an adhesive which retains adequate strength at high temperatures. Specimen size and availability also is limited. At present, the length of the specimen is limited to about 130 millimeters ( 5 inches) by cost and available processing equipment. The short length of the specimen dictates the use of fairly high temperature grips. Otherwise, the thermal gradients would cause significant stresses within the specimen. This requires the ends of the specimen to be held at a high enough temperature so that tabs cannot be used. Most gripping fixtures induce stress concentrations within the specimen which can cause the 
specimen to fail near the grips outside of the gage section. To promote failure within the gage section it is necessary to neck down the specimen. Some researchers have tested SiC/LAS composites which have been necked down in both the width and the thickness directions (refs. 1-5,8). The reduction of the specimen through the thickness has been shown to reduce the strength of the specimen. This is due to unavoidable damage to the fibers of the outer lamina during machining of the specimen (ref. 8). On the other hand, testing specimens (SiC/LAS or SiC/CAS II) which have reduced sections through the width only have resulted in fairly successful tensile tests (refs. 6,7). Figure 5 shows a SiC/LAS specimen with dimensions as used by researchers at the University of Dayton Research Institute. This specimen used a single radius for the reduced gage section width (ref. 6). On the other hand, researchers at General Electric used two radii for the reduced gage section of the SiC/CAS II specimens (ref. 7). For the testing of SiC/RBSN or SiC/SiC, it is recommended that the specimen be reduced in the gage section through the width and have a constant thickness throughout (ref. 10). Some researchers also have recommended this specimen configuration for SiC/LAS composites (ref. 2). Caution, however, must be exercised in the design of the specimen shape. A specimen which has a reduced section through the width can fail by fracturing at the radius with the crack propagating longitudinally along the fibers up through the grip section. The use of finite element analysis (FEA) is recommended to optimize the specimen shape and increase the likelihood of failure in the gage section. Selected strength results from room temperature tests can be utilized for validating the finite element analysis.

\section{FURNACES AND HIGH TEMPERATURE CHAMBERS}

Many techniques are available for raising the temperature of the gage section of a tensile specimen to the desired temperature of $1650^{\circ} \mathrm{C}\left(3000^{\circ} \mathrm{F}\right)$. In addition to the temperature requirements, it is necessary to have access to the specimen for such instrumentation as extensometers or optical strain measuring devices and some type of temperature measuring gage. The furnace has to operate successfully for a reasonable duration in an inert or an oxidizing atmosphere. Also, due to the limited length of the specimen, the furnace has to be generally small. For 
adequate representation of material strength characteristics, it is desirable to have at least a 25 millimeter ( 1 inch) gage section with a homogeneous temperature distribution. Heating techniques include resistance and induction furnaces, radiant furnaces, laser heating, radio frequency induction heating, and direct electrical heating (ref. 13). These techniques are discussed in detail in the following paragraphs. Indirect heating techniques, such as the resistance, induction, and radiant furnaces are relatively insensitive to the specimen material and coatings. Their operating characteristics are reproducible including the specimen temperature profile. Disadvantages include possible susceptor or heating element material problems in air, less access to the specimen gage section, and less efficient heating than by direct means.

Direct heating techniques, such as laser heating, radio frequency induction heating, and direct electrical heating offer a relatively simple system and are efficient techniques. The latter two techniques of course require a conductive specimen. In addition, direct heating requires minimal insulation and offers good access to the specimen for strain and temperature measuring devices. Disadvantages include power supply matching problems since they are dependent on the material of the specimen and it is difficult to reproduce the testing conditions. It is also difficult to control the specimen temperature profile. Furnaces can be set up in one of two ways for maintaining an inert atmosphere. One technique, used at Southern Research Institute, employs an open furnace which utilizes constant purging of an inert gas (ref. 10). This eliminates the complexities of sealing the furnace but it also increases the turbulence within the furnace. The other technique, which has been recommended by other researchers (ref. 7), is to seal the furnace, which minimizes the flow of gases and reduces the turbulence at high temperatures. The reduction in turbulence is required with the use of extensometers with alumina rods or with optical strain and optical temperature measuring devices. Researchers at General Electric Company have two different furnaces: one for testing in an inert atmosphere and another for testing in air (ref. 7). Both furnaces are sealed, however, to reduce the gas turbulence. 


\section{RESISTANCE AND INDUCTION FURNACES}

Resistance and induction furnaces are the most common form of heating for general materials laboratory work (ref. 13). They consist of electrical resistance coils supported by a refractory molding. Resistance furnaces have the heating elements in the same chamber as the specimen. In contrast, induction furnaces have the elements isolated from the chamber containing the specimen. This allows the elements to operate in a different atmosphere relative to the specimen. The coils usually consist of multiple windings such that a number of zones can be defined. The control of the individual zones can be used to partly compensate for the heat loss to the grips in a tensile testing system. A common and convenient form of this furnace has the chamber divided into half cylinders which are hinged together. This allows for easy setup due to the ready access to the grips and the specimen. The split furnace also allows the use of windows for instrumentation such as mechanical extensometers or various optical devices.

Different materials are available for use as heating elements depending on the desired temperature range and environment. Platinum alloys can be used up to $1800^{\circ} \mathrm{C}\left(3300^{\circ} \mathrm{F}\right)$ in an inert or oxidizing atmosphere (ref. 14) and some ceramics (e.g. silicon carbide) can be used to well over $2000^{\circ} \mathrm{C}\left(3600^{\circ} \mathrm{F}\right.$ ) (refs. 13-15), but only in an oxidizing atmosphere. Molybdenum disilicide (Super Kanthal) can be used to $1750^{\circ} \mathrm{C}\left(3180^{\circ} \mathrm{F}\right.$ ) in air and $1550^{\circ} \mathrm{C}\left(2820^{\circ} \mathrm{F}\right.$ ) in argon (ref. 14). Researchers at the Naval Research Laboratory have applied a platinum-rhodium element furnace in the tensile testing of ceramic composites. This permitted a gage section temperature of $1500^{\circ} \mathrm{C}\left(2730^{\circ} \mathrm{F}\right.$ ) (ref. 16). Researchers at General Electric Company have two different furnaces using a Super Kanthal element furnace for testing in air and a tungsten element furnace for testing in an inert atmosphere (ref. 7). The tungsten elements can be used up to a temperature of $2550^{\circ} \mathrm{C}\left(4620^{\circ} \mathrm{F}\right)$ in a vacuum or inert atmosphere. Super Kanthal elements have been used at the National Bureau of Standards in a split furnace for testing at $1300^{\circ} \mathrm{C}\left(2370^{\circ} \mathrm{F}\right)$ in air (ref. 17).

Temperature is typically varied by some form of controller. The controller usually utilizes a thermocouple placed near the specimen gage section to monitor the temperature. Researchers have been able to control the temperature to $\pm 0.5^{\circ} \mathrm{C}$ at $1700^{\circ} \mathrm{C}$ with the use of thermocouples attached to the specimen gage section 
(ref. 18). With the testing of ceramic specimens, problems may be encountered in reaction of the thermocouple with the specimen.

The resistance and induction furnaces are highly developed and reliable devices. There are many commercially available units which can be adapted to most applications. Due to the limited length of the SiC/RBSN composite specimens and the use of cooled grips when testing in air, these furnaces would have to be quite short with two zones at most. With a split furnace, the windows or optical devices would have to be realigned every time the furnace is opened up. A closed furnace would make access to the specimen difficult but realignment of the optics would not be required. When considering the heating elements, platinum-rhodium or Super Kanthal offer a quick response and a working range that includes the desired temperature of $1650^{\circ} \mathrm{C}\left(3000^{\circ} \mathrm{F}\right.$ ) in an oxidizing atmosphere. Tungsten elements can also be used at the desired temperature but only in an inert environment. In addition, tungsten elements also offer a quick response. On the other hand, silicon carbide elements offer a much slower response than metallic elements requiring more time for heating or cooling. Unfortunately, use of silicon carbide elements is limited to an oxidizing atmosphere only. The oxygen is needed to form a $\mathrm{SiO}_{2}$ layer on the outer surface of the element which prevents the diffusion of the silicon into the atmosphere. The advantage of the silicon carbide elements is that they last longer and can be used at higher temperatures which can be a long term advantage.

\section{RADIANT FURNACES}

One type of radiant furnace uses high intensity lamps with reflectors focused onto the specimen. The furnace typically has four lamps equally spaced in a circle about the specimen axis. The reflectors are usually air or liquid cooled. As with resistance and induction furnaces, radiant furnaces can be split with the two halves being hinged together. This allows for easy access to the specimen and the grips.

Another configuration uses multiple lamps placed in close proximity to the specimen surface. The lamps are arranged such that various heating zones exist allowing for the minimization of thermal gradients along the length of the specimen gage section.

Radiant furnaces use the same type of controller as the resistance and induction furnaces. These 
controllers use a thermocouple which is placed on or near the surface of the specimen gage section.

Depending on the emissivity of the specimen surface, the specimen can be heated to well over $1000^{\circ} \mathrm{C}$ $\left(1830^{\circ} \mathrm{F}\right)$. Higher temperatures can be attained with specimens having emissivities approaching that of a black body. Due to the single zone heating, the reflector type of furnace requires a long specimen so that a large enough gage section would have a homogeneous temperature distribution. The multiple lamp configuration offers multi-zone heating so that shorter specimens can be utilized.

Some researchers have used radiant furnaces with tungsten-halogen lamps for testing SiC/LAS composites up to temperatures of $1000^{\circ} \mathrm{C}\left(1830^{\circ} \mathrm{F}\right.$ ) (refs. 4,6$)$. Others have tested monolithic ceramics up to temperatures of $1600^{\circ} \mathrm{C}\left(2910^{\circ} \mathrm{F}\right)$ (ref. 19) with the use of infrared

lamps.

The reflector type of radiant furnaces offer good access to the specimen, although the radiation heat loss from the specimen can be quite significant. In contrast, the multiple lamp type of radiant furnaces offer minimal radiation heat loss. Access to the specimen for various instruments is limited with the multiple lamp configuration.

Radiant furnaces offer a rapid response compared to resistance and induction furnaces. This is due to their minimal thermal inertia. The furnace can be quickly cooled and reheated. This can be a considerable advantage when a large number of specimens have to be tested for statistical strength analysis. The trade off is in the higher initial and maintenance costs of the radiant furnaces.

\section{LASER HEATING}

A specimen can be heated by using a powerful laser, such as a carbon dioxide $\left(\mathrm{CO}_{2}\right)$ laser. The $\mathrm{CO}_{2}$ laser operates at a wavelength of 10.6 microns which is in the infrared region of the electromagnetic wave spectrum. The technique is best suited for planar specimens. With the use of a beam splitter and mirrors, both sides of a specimen can be heated. The technique minimizes material problems but is sensitive to surface reflectivity, which can be a problem as the specimen oxidizes during a test. In addition, an unobstructed line of sight is required for the laser. This technique does produce a significant axial thermal gradient which 
can be detrimental since it is important to have a specimen gage section with a near homogeneous temperature distribution (ref. 14).

\section{RADIO-FREQUENCY AND DIRECT ELECTRICAL HEATING}

Radio-frequency heating is a simple technique which heats a specimen by the use of electromagnetic radiation. It consists of a liquid-cooled induction coil with relatively few turns, with the specimen located at the axis of the coils. The technique gives an unobstructed view of the specimen, allowing the use of mechanical or optical strain measuring and temperature measuring devices. The heating can be highly localized permitting the use of short specimens.

The matrix of the SiC/RBSN specimens is a poor electrical and thermal conductor. As a result, the radio-frequency heating technique is not recommended for use with the Sic/RBSN composite specimens, since the efficiency of the furnace is proportional to the electrical and thermal conductivities of the specimen. The technique would also produce significant axial thermal gradiants due to the short length of the specimen.

Direct electrical heating is a technique in which large amounts of current are passed directly through the specimen, permitting totally unobstructed view of the specimen. Unfortunately as with the radio-frequency heating method, this technique requires a specimen with good electrical conductivity. In addition, this technique induces significant axial thermal gradiants which cannot be adequately controlled. As a result, direct electrical heating cannot be utilized. It should also be noted that these techniques require either very high voltages or large amounts of current. Consequently, these systems require very bulky and costly equipment which can also be a significant disadvantage relative to other heating techniques.

\section{STRAIN MEASURING TECHNIQUES}

There are many techniques available for measuring strain in a tensile specimen. These methods include strain gages, the crosshead displacement of a tensile testing machine, mechanical extensometers, or various optical methods. Stated again, our initial objective is the tensile testing of SiC/RBSN and SiC/SiC 
composites at $1650^{\circ} \mathrm{C}\left(3000^{\circ} \mathrm{F}\right)$ in an inert or an oxidizing atmosphere. Due to the harsh environment in which the specimens are to be tested, many of the conventional strain measuring techniques cannot be used. From room temperature tensile tests of silicon carbide fiber reinforced silicon nitride (ref. 20) it has been shown that for this material, first matrix cracking occurs at approximately 0.1 percent strain. For the same specimen, the ultimate strength occurs at approximately 0.5 to 0.6 percent strain. This is an approximate range in which the strain measuring device has to operate. Initially a brief description of the more commonly used mechanical strain measuring techniques is given. Major advantages and disadvantages of their application to high temperature tensile testing of ceramic composites are discussed. Next, a general overview is given of various optical techniques and their advantages and disadvantages noted (ref. 21).

\section{CURRENTLY USED TECHNIQUES FOR MEASURING STRAIN}

Currently, many of the strain measuring methods applied to high temperature material characterization tests are mechanical. These techniques include strain gages, mechanical extensometers, and the crosshead displacement measurement method.

Strain gages are well developed, widely used, and offer low cost. In general, strain gages are simple to install and offer adequate accuracy. Unfortunately, strain gages are intolerant of elevated temperatures. At present, the highest attained working temperature is approximately $800^{\circ} \mathrm{C}\left(1470^{\circ} \mathrm{F}\right.$ ) (ref. 22). It is known that, at elevated temperatures, problems with attachment of the gage to the specimen and oxidation are encountered. In addition, there are problems with the connection of electrical leads. Thermal compensation is also difficult, resulting in subsequent lower accuracy. Mechanical extensometers can be applied at high temperatures and offer adequate accuracy. This technique usually requires divots or notches to be cut in the specimen surface. The notches or divots may cause significant stress concentrations in a specimen which can initiate first matrix cracking. Recently, various extensometer systems have been marketed which do not require notches or divots in the specimen surface. These systems use a light pressure applied to the extensometers to hold them against the specimen surface. Problems which may be encountered include slipping of 
the extensometers during a test (ref. 7) or breaking of the rods when the specimen fractures (refs. 1,2). The extensometers can also act as a heat sink which would cause undesirable thermal gradients within the gage section of the specimen. The materials used for the extensometers also limit the performance. Quartz rods are limited to approximately $1090^{\circ} \mathrm{C}\left(2000^{\circ} \mathrm{F}\right)$. On the other hand, alumina rods can be used at the desired temperature of $1650^{\circ} \mathrm{C}\left(3000^{\circ} \mathrm{F}\right)$ but alumina is very sensitive to air circulation (ref. 6). The air circulation about the rods causes different thermal expansion rates at various points in the alumina, producing bending in the rods, which induces a random signal into the extensometer system. The induced noise can be significant. As a result, the use of extensometers with alumina rods requires heavy insulation to minimize air circulation about the rods (ref. 7).

The crosshead displacement method is extremely simple and can be used with most tensile testing systems. It is also very inexpensive. The main disadvantage is that it offers very low accuracy. With the crosshead far removed from the specimen gage section it is difficult if not impossible to account for nonhomogeneous strain in a specimen. It is also difficult to account for the strain in the load train. Consequently, this method is not suited for applications where high precision is required.

\section{OPTICAL STRAIN MEASURING TECHNIQUES}

Optical methods offer increased accuracy over the crosshead displacement technique and do not have the breakage problems of the mechanical extensometers. There are a number of different types of optical methods available for measuring strain or displacement. These include laser interferometry, electrooptical tracking, speckle photography, speckle interferometry, and holography. In addition, photoelastic coatings and conventional Moire methods can be used to measure in-plane strain.

Difficulties can be encountered with the application of an optical strain measuring technique to high temperature tensile testing in an oxidizing or inert atmosphere. Turbulence within the furnace causes variations in atmospheric density which cause the index of refraction of the gas to change. For most of the optical methods the turbulence causes optical noise 
which can be partly accounted for. The furnace window can cause additional changes in diffraction which can also be compensated for. If an open window is used, then the flow of hot gases just increases the turbulence. Therefore, one has to exercise caution so that the resulting optical noise from the increased turbulence does not interfere excessively with the desired measurements.

Some of the above optical strain measuring techniques usually pose serious problems when applied to high temperature tensile testing. These include photoelastic coating methods, conventional Moire techniques and holography.

Photoelastic coating methods are simple, well developed, and offer adequate accuracy. This technique requires a coating to be placed directly on the specimen surface. The coating is required to have a similar Poisson's ratio to that of the composite specimen and, in addition, it would have to be maintained at high temperatures in an oxidizing atmosphere. In general, the photoelastic methods are limited to temperatures of only a few hundred degrees. Conventional Moire techniques require a grating to be placed directly on the specimen surface. As with the photoelastic methods, conventional Moire techniques are simple and well developed. Also like the photoelastic methods, the Moire methods are generally limited to lower temperatures, due to difficulties in maintaining the grating. Although in one recent experiment, the Moire technique has been applied at a temperature of $1370^{\circ} \mathrm{C}\left(2500^{\circ} \mathrm{F}\right.$ ) (ref. 23), but this is below the desired test temperature. Holography is a truly noncontact optical technique. It does not require any special preparation of the surface of the specimen and it is also extremely sensitive. For example, holographic interferometry using a helium-neon laser has a sensitivity of approximately 0.3 microns (12 microinches) (ref. 21). As a result, the system has to be isolated from any external vibrations, making the installation or setting-up of the system quite tedious. The system also requires a laborious alignment of optics. Unfortunately, holography is best suited to measure out-of-plane displacements such as those usually encountered in vibration analysis. As a result, most holography applications are for flexural or transverse vibrational analysis of a specimen. 


\section{REAL TIME TECHNIQUES}

In this section a description of the various techniques which provide real time output is given. Due to availability of this real time output, all these methods can be used in a closed loop tensile testing system. Advantages and disadvantages of application to the high temperature tensile testing of ceramic composites are discussed for each method. The general specifications such as typical gage lengths, sensitivities, and ranges also are summarized.

It should be noted that these methods do not offer a full field view of the strains or displacements in a specimen; the output is just an average strain or displacement over the gage length of the specimen. These methods track two fiducial marks, with one at each end of the gage section.

The fiducial marks used with the majority of the real time techniques are flags which are either bonded or mechanically fastened to the specimen. Due to the harsh environment in which the specimen is to be tested, serious problems with flags may arise. For example, the adhesive used to bond the flags to the specimen may not hold causing the flags to slip or even fall off the specimen. This would invalidate all the strain data from a test. On the other extreme, the flags may react with the specimen causing stress concentrations which can initiate matrix cracking in the immediate vicinity of the flags. For the mechanically fastened flags slipping may cause erratic data output. As with the bonded flags, the mechanically fastened flags can also react with the specimen to produce undesirable stress concentrations.

\section{A. LASER INTERFEROMETRIC STRAIN GAGE}

The laser interferometric strain gage (LISG) (ref. 24), also referred to as the Sharpe method, consists of a single laser which illuminates two fiducial markings on the specimen. The markings reflect the laser light to either side of the incident beam where each reflected beam projects a set of interference fringes. The motion of the fringes is proportional to the change in the relative displacement of the markings on the specimen. Figure 6 shows a schematic of the LISG. The change in the relative displacement between the markings is given by (ref. 21): 


$$
\Delta \mathrm{d}=\frac{\lambda}{\sin \alpha} \frac{\Delta \mathrm{m}_{1}+\Delta \mathrm{m}_{2}}{2}
$$

Where: $d=$ the relative displacement of the markings $m_{1}$ and $m_{2}=$ the fringe orders

$\lambda^{1}=$ the wavelength of the incident laser beam $\alpha=$ the angle between the incident laser beam and the reflected beams

The $\left(\Delta m_{1}+\Delta m_{2}\right) / 2$ term in equation (1) gives the mean value of the change in the fringe orders. This averaging accounts for the rigid body motions. The fringes can impinge on a screen and their movement measured manually with respect to a fiducial mark, or phototransistors or photoresistors can be used to sense the motion of the fringes. With the use of a minicomputer, the LISG has been applied to a closed loop tensile testing system (ref. 21).

The markings consist of pyramidal shaped indentations produced by a Vicker's diamond micro-hardness indenter. These indentations can be placed directly into the specimen surface or in the surface of a tab which can be adhesively bonded to the specimen. One of the requirements for the markings is that the surface of the indentations must be reflective.

The application of the sharpe method to the testing of ceramic composites would require the use of adhesively bonded tabs. Ceramics are hard and brittle making it difficult to place accurate Vicker's indentations directly in the specimen surface. Also, recent observations have shown that the surface of some ceramics is translucent (ref. 21). As a result, the use of indentations directly in the specimen surface would not meet the requirements for a highly reflective surface. In addition to the unique problems associated with the use of ceramic specimens, the surrounding environment will be an oxidizing atmosphere (air) at $1650^{\circ} \mathrm{C}\left(3000^{\circ} \mathrm{F}\right)$. This would typically require the use of platinum tabs and a ceramic cement. The gage length can be varied from 100 microns $(3.9 \mathrm{mils})$ to about 800 microns ( $31 \mathrm{mils}$ ). The gage length is relatively small. As a result, there is a high probability that first matrix cracking may occur outside of the selected gage section. This would prevent the strain gage from registering the sudden increase in strain due to matrix cracking. Another problem at high temperatures is that the light emitted by the specimen can saturate the 
photodiodes at the wavelength of the laser making the LISG ineffective (ref. 24). This problem can be overcome with the use of a more powerful laser and/or the utilization of an optical filter.

Typical specifications for this method, when used for ceramic testing, are shown in Table I. Also shown in this table are the conditions under which the

Table I: LASER INTERFEROMETRIC STRAIN GAGE (LISG) (ref. 21)

$\begin{array}{ll}\text { MAXIMUM APPLIED } & -1400^{\circ} \mathrm{C}\left(2550^{\circ} \mathrm{F}\right) \\ \text { TEMPERATURE } & - \text { PLATINUM TABS } \\ \text { TARGET } & -100 \text { TO } 800 \text { MICRONS } \\ \text { GAGE LENGTH } & (3.9 \text { TO } 31 \text { MILS }) \\ \begin{array}{l}\text { DISPLACEMENT } \\ \text { RANGE }\end{array} & -300 \text { MICRONS (12 MILS) } \\ \text { RESOLUTION } & -1 \text { MICRON (39 MICROINCHES) } \\ \text { ERROR } & -2 \text { TO } 3 \text { PERCENT }\end{array}$

technique has been applied. The maximum range of 300 microns ( $12 \mathrm{mils}$ ) is actually limited by the resolution of the photodetectors. For values greater than 400 microns ( $16 \mathrm{mils}$ ) the fringes become too fine for the photodetectors to resolve (ref. 21). Out-of-plane displacements less than 25 microns ( $1 \mathrm{mil}$ ) do not cause any significant errors (ref. 21). Convection currents about the specimen have minimal effects due to the small gage length. The LISG is not recommended for use with the high temperature tensile testing of unidirectional fiber reinforced ceramic composites due to the required small gage length. As noted before, there is a high probability that first matrix cracking can occur outside of this gage section.

\section{B. OPTICAL STRAIN ANALYZER}

The optical strain analyzer as used by Southern Research Institute consists of two telescopes mounted in a "piggy-back" arrangement (ref. 12) as shown in 
Fig. 7. The system is an electro-mechanical-optical design which tracks two flags on either end of the gage length of a tensile specimen. The upper telescope tracks the upper flags carrying with it the lower telescope. The lower telescope at the same time tracks the lower flag. Elongation is measured as the displacement of the image in the lower telescope. Due to the relative motion of the scopes, the rigid body motions do not affect the displacement measurement from the gage section.

Each flag is a pair of targets on opposite sides on the specimen as shown in Fig. 8. Using a dual optical system with an average output minimizes any irregularities due to non-axial motion of the flags. High intensity lights are shined through the slots in the targets which are picked up by the telescopes. For high temperatures where the targets become self luminous, the high intensity lights are not required. For each scope, the light passing through the targets from both sides of the specimen are formed on a rectangular aperture. The aperture contains small slits which permit passage of the upper and lower edges of the light beams. An optical chopper breaks up the light into pulses with a fixed rate which a photodiode then converts to an alternating voltage. The aperture and the chopper are illustrated in Fig. 9. The light beams going to the apertures are blocked alternately by the chopper. When the scope is at the null point the output from the photodiode, due to the light from the apertures, is constant. This is shown in Fig. 10a. When the flag moves due to specimen deformation, the amount of light passing through the apertures changes. As a result, the output from the photodiodes varies as the light source from the apertures alternates. This is illustrated in Fig. 10b. Using a closed loop system, the scopes are repositioned to the point where the output voltage is the same. The displacements of the scopes are recorded which corresponds to the displacement of the specimen gage section. For system power amplification, commercial high fidelity audio amplifiers are used.

In high temperature tensile testing, this system has been applied to the testing of carbon/carbon composites in an inert atmosphere. The flags were made of carbon and were clamped onto the specimen using carbon fasteners. The design has been perfected to the level where the fracture of the carbon specimen is not affected (ref. 25). In the case of a ceramic composite specimen in an oxidizing atmosphere, the flags would have to be redesigned. This includes selecting a 
material and finding a way to attach the flags to the specimen. As noted before, there is always the possibility of the material of the flags reacting with the specimen causing a stress concentration. On the other hand, it is possible for the flags to slip on the specimen making the data from the test invalid. In the past, data was collected from hundreds of tensile tests of carbon/carbon composites where only one side was monitored and then where both sides were monitored. It was found that both techniques resulted in the same average strain but the range or percent error was reduced significantly by monitoring both sides of a specimen. Therefore, it is highly recommended that both sides of the specimen should be monitored for strain (ref. 10).

The optical strain analyzer allows a maximum displacement of 6.35 millimeters $(250 \mathrm{mils})$ without any readjustment. It has a precision of 1.27 microns ( 50 microinches) (ref. 25). General specifications are summarized in Table II.

TABLE II: OPTICAL STRAIN ANALYZER

(ref. 21)

MAXIMUM

TEMPERATURE $\quad->2000^{\circ} \mathrm{C}\left(3600^{\circ} \mathrm{F}\right)$

GAGE LENGTH - 30 MILLIMETERS ( 1.2 INCHES)

DISPLACEMENT

RANGE

- 6.4 MILLIMETERS (0.25 INCHES)

RESOLUTION -1.3 MICRONS (51 MICROINCHES)

ACCURACY $\quad- \pm 2.5$ MICRONS ( \pm 98 MICROINCHES)

Electrooptical tracking is a strain measuring technique which is recommended by many researchers for use with the high temperature tensile testing of ceramic composites (refs. 8,26). The optical strain analyzer offers optimum performance for use with high temperature tensile testing. The optical strain analyzer is an old system but it has been improved to the point where it is highly reliable and offers good performance.

\section{ZIMMER ELECTRO-OPTICAL EXTENSOMETER}

The Zimmer system has been utilized by various 
researchers at Pennsylvania State University, National Bureau of Standards (NBS) (ref. 17), and the Government Industrial Research Institute of Japan (ref. 27) for the testing of ceramics. These tests included high temperature tensile tests. The system consists of high intensity lights which are shined past a set of flags mounted on a tensile specimen. The flags block a portion of the light and the resulting shadow is projected on an array of photosensors. The position of the shadow on the photosensors changes directly in proportion with the change in distance between the flags when the specimen is deformed. As a result, the output from the photosensors is used to determine the change in relative displacement of the flags.

The flags consist of alpha silicon carbide ( $\alpha-S i C)$ which are bonded to the specimen. The flags sinter to the specimen surface during high temperature testing (ref. 28). The flags are illustrated in Fig. 11. In addition, researchers at NBS attached platinum wires to each flag to enhance the visibility of the flags.

TABLE III: ZIMMER ELECTRO-OPTICAL EXTENSOMETER

(refs. 17 and 28 )

MAXIMUM

TEMPERATURE $\quad-\sim 1600^{\circ} \mathrm{C}\left(2910^{\circ} \mathrm{F}\right)$

GAGE LENGTH - 25 MILLIMETERS ( 1 INCH)

RESOLUTION - 1 MICRON (39 MICROINCHES)

ACCURACY $\quad- \pm 2$ MICRONS ( \pm 79 MICROINCHES)

The zimmer system has been applied with a specimen gage section temperature of $1300^{\circ} \mathrm{C}\left(2370^{\circ} \mathrm{F}\right)$ in air (ref. 28). Approximate values for resolution, accuracy, and other relevent information for the zimmer system are shown in Table III. The maximum test temperature at which this system can be utilized is approximately $1600^{\circ} \mathrm{C}\left(2910^{\circ} \mathrm{F}\right)$ with the use of an optical filter (ref. 17).

\section{ZYGO LASER DIMENSION SENSOR}

The zygo Laser Dimension Sensor is a relatively new system. Consequently, it has not been applied to the high temperature tensile testing of ceramic composites 
yet, although various researchers at General Electric, National Bureau of Standards, and Corning are presently evaluating the system for this purpose. The system uses a scanning laser which is shined past a pair of flags on a tensile specimen and onto a receiver. The receiver senses the edge of the shadow from the flags and with the use of a processor the relative displacement of the flags is determined.

Table IV contains selected data for the system. With the use of an optical filter, the system can handle specimen temperatures up to $1900^{\circ} \mathrm{C}\left(3450^{\circ} \mathrm{F}\right)$. The system can also measure displacement up to 115 millimeters $(4.5$ inches $)$. The accuracy is \pm 0.0025 millimeters $( \pm 0.0001$ inches) (ref. 29).

Table IV: ZYGO LASER DIMENSION SENSOR (ref. 29)

$\begin{array}{ll}\begin{array}{l}\text { MAXIMUM } \\ \text { TEMPERATURE }\end{array} & -1900^{\circ} \mathrm{C}\left(3450^{\circ} \mathrm{F}\right) \\ \text { GAGE LENGTH } & -<115 \text { MILLIMETERS }(4.5 \text { INCHES }) \\ \text { ACCURACY } & - \pm 0.0025 \text { MILLIMETERS }( \pm 0.0001 \\ & \text { INCHES })\end{array}$

4. SPECKLE PHOTOGRAPHY AND SPECKLE INTERFEROMETRY

Speckle methods are truly non-contact techniques that require no special surface preparation. These techniques use laser illumination to form the speckles. The speckles are actually random points of interference of light reflected from various depths of a diffusely reflecting surface. Speckle methods offer a full field view allowing for the derivation of strains or displacements at any point on the surface of the specimen. However, these methods do not operate in real time.

In speckle photography, a single divergent laser is used to illuminate a diffusely reflecting surface producing speckles. Next, a photograph is taken of the surface before and after deformation of the object by double exposure of the same film. The resulting 
negative, called a specklegram, is used to derive displacements at various points on the surface of the specimen.

Speckle interferometry has a specimen illuminated by two incident laser beams which are symmetric about the normal to the surface. The two incident beams interfere producing a grating on the specimen surface. As with speckle photography, a photograph is taken before and after deformation of the specimen. The same film is used for each photograph; therefore the film is double exposed. The superposition of the gratings produces Moire fringes which are used to derive displacements at various points on the specimen surface.

Another form of speckle interferometry is one in which the speckle pattern is sheared using a double aperture camera in which a prism is placed in front of one or both apertures. Speckle shearing interferometry offers higher quality fringes than speckle photography and conventional speckle interferometry. In addition, it offers increased flexibility, and a relatively simple setup compared with other speckle methods. A more detailed description of the various speckle methods is given in reference 21 .

With ceramics, it is generally desirable to test as many specimens as possible due to the statistical nature of their failure strength. In addition, because of the long cycle times of the various speckle methods and the limited range these speckle methods offer, these techniques are not recommended for the high temperature

TABLE V. (ref. 21)

SPECKLE PHOTOGRAPHY

DISPLACEMENT

RANGE

- 36 MICRONS ( 1.4 MILS)

PRECISION $\quad-0.36$ MICRONS (14 MICROINCHES)

SPECKLE INTERFEROMETRY

DISPLACEMENT

RANGE

- 6 MICRONS (240 MICROINCHES)

PRECISION

- 0.04 MICRONS ( 1.6 MICROINCHES) 
tensile testing of ceramic composites. Some general data for speckle photography and speckle interferometry are shown in Table $V$. These speckle methods are overly sensitive to out-of-plane motion and require a laborious alignment of optics. Other problems which may be encountered with the high temperature testing of ceramic composites include changing of the surfaces of the specimen due to oxidation during the test. Recent observations have shown that the surface of some ceramics are actually translucent which may cause additional problems with speckle methods (ref.21).

\section{TEMPERATURE MEASURING METHODS}

The desired temperature of $1650^{\circ} \mathrm{C}\left(3000^{\circ} \mathrm{F}\right)$ for the testing of ceramic composites limits the number of temperature measuring techniques which can be applied. Available methods include use of platinum-rhodium thermocouples and various optical techniques. Many researchers have used thermocouples in high temperature testing in air (refs. $4,18,19,30,31$ ), although some difficulties can arise with the attachment of the thermocouple to the surface of the specimen. Also, attached thermocouples can cause thermal gradients within the specimen.

Alternatives to thermocouples are various types of optical pyrometers. These pyrometers determine the temperature of a body from the energy that is emitted by the specimen. As the temperature of a specimen is increased, the total energy radiated from the surface increases. This is illustrated in Fig. 12. The total radiated energy is a function of the specimen's temperature and surface condition. For an ideal radiator or blackbody the total energy, integrated over all wavelengths, is a function of temperature. This relation is shown by equation (2) which is known as the Stefan-Boltzmann law:

$$
\mathrm{E}_{\mathrm{b}}=\sigma \mathrm{T}^{4}
$$

where: $E_{\mathrm{b}}=$ the energy radiated per unit time and per unit area by the ideal radiator

$$
\begin{aligned}
\sigma= & 5.669 \times 10^{-8} \mathrm{~W} / \mathrm{m}^{2} \mathrm{~K} \mathrm{~K}^{4}\left(0.1714 \times 10^{-8}\right. \\
& \text { Btu/h } \left.\mathrm{ft}^{2} \mathrm{o}_{\mathrm{R}}^{4}\right) \text { Stefan-Boltzmann constant } \\
\mathrm{T}= & \text { absolute temperature }
\end{aligned}
$$

Unfortunately, most bodies are not ideal radiators. As a result, most bodies radiate less energy than a perfect 
blackbody. The energy emitted from a real body is related to the energy radiated from an ideal blackbody by the emissivity constant. This is shown by equation (3):

$$
E=\varepsilon E_{b}
$$

where: $E=$ the energy radiated per unit time and per unit area by a non-ideal radiator

$\varepsilon=$ emissivity

In a real body, the emissivity varies with temperature and the wavelength of the radiation. A certain type of non-ideal radiator, known as a gray body, has a constant emissivity which does not change with the wavelength. Figure 13 shows the emissive power as a function of wavelength for the gray body and a real body relative to a blackbody. The various optical pyrometers which are available use this radiated energy to determine the temperature of the specimen.

In general, radiation pyrometers collect the total radiated energy covering the ultraviolet (UV), visible, and infrared (IR) wavelengths. The energy source is assumed to act like a gray body with constant emissivity and the emissivity is manually entered. The units usually are not focused. These devices are typically hand held units used for measuring temperatures of kilns, furnaces, and oxidized metallic surfaces. The response time is typically four to six seconds. A common temperature range is $700^{\circ}$ to $1300^{\circ} \mathrm{C}$ $\left(1290^{\circ}\right.$ to $\left.2370^{\circ} \mathrm{F}\right)$, but with the use of calibrated diaphragms, the temperature range can be extended to $2000^{\circ} \mathrm{C}\left(3630^{\circ} \mathrm{F}\right)$ (ref. 32). Radiation pyrometers offer limited accuracy due to the limited sensitivity of most detectors. Most detectors are sensitive to only a fraction of the total energy emitted by a body, and are more sensitive at some wavelengths than at other wavelengths (ref. 33). The other source of error is the assumed emissivity value. At high temperatures, this device can easily be in error by several hundred degrees in temperature.

IR pyrometers also are hand held units with either focused or nonfocused optics. These devices determine the temperature of the radiation source from the IR region of the emitted energy. This type of device can be used for temperatures within the range of $-50^{\circ}$ to $4200^{\circ} \mathrm{C}\left(-58^{\circ}\right.$ to $\left.7590^{\circ} \mathrm{F}\right)$. As with the radiation pyrometers, this technique assumes the energy source acts like a gray body with a constant emissivity as a 
function of wavelength. The IR pyrometer is a narrow band or monochromatic pyrometer in contrast with the radiation pyrometer which is a wide band or broad range pyrometer (ref. 32). The IR pyrometer also offers less sensitivity than the radiation pyrometer but it offers increased accuracy.

Ratio pyrometers measure the energy radiated at two or more selected wavelengths. The technique assumes that the emissivity does not change with temperature at each of the selected wavelengths. With the appropriate wavelengths selected, the ratio pyrometer offers increased accuracy over other types of optical pyrometers, especially if the emissivity of a body is unknown (ref. 34). Typically the ratio pyrometer can be used for measuring temperature from $800^{\circ}$ to $2500^{\circ} \mathrm{C}$ $\left(1470^{\circ}\right.$ to $4530^{\circ} \mathrm{F}$ ) (ref. 32 ). Oak Ridge National Laboratories recently has utilized a ratio pyrometer to measure and control the temperature of an alumina specimen at approximately $1000^{\circ} \mathrm{C}\left(1830^{\circ} \mathrm{F}\right)$.

Finally, a commonly used optical pyrometer is the disappearing filament type. This technique compares the brightness of the radiation source with a known source (filament). The technique is subject to error due to human interpretation and eye fatigue, although automatic models can minimize the errors (ref. 32).

The advantage of these optical pyrometers is that they are truly non-contact methods which eliminate the problems of attachment. Some researchers who are presently using thermocouples intend to use an optical pyrometer once other problems of high temperature tensile testing have been overcome (ref. 6). Optical pyrometers also have some drawbacks. Many of these devices depend on a constant emissivity which may actually change during a test. The change in emissivity of a ceramic specimen can be due to oxidation of the specimen surface during a high temperature test in air. For some materials, the emissivity can change by an order of magnitude (ref. 33). This change in emissivity can lead to significant errors in determining the temperature of the specimen gage section. Additional input from the walls of the high temperature chamber and the hot gases which are in the near or in immediate proximity to the specimen may also be significant.

\section{CONCLUSION}

Many of the currently available components for a high temperature tensile testing system have been 
surveyed and evaluated. The tensile testing of longitudinal fiber reinforced ceramic composite specimens at temperatures up to $1650^{\circ} \mathrm{C}\left(3000^{\circ} \mathrm{F}\right)$ in air results in a highly demanding application for many of the components. Consequently, some compromises have to be accepted with some of the components.

Due to the limitations imposed by the specimen's characteristics, such as a relatively low shear strength as compared to the longitudinal strength, it has been determined that some form of friction grips would offer optimum performance. The use of mechanical wedges may offer the simplest and most cost effective solution for the friction grips. A silicon carbide insert would have to be utilized between the grips and the specimen. The tests which are to be conducted in air would require the use of cooled grips due to the lack of a grip material which can withstand the test temperatures and offer adequate strength without serious degradation. The material of the grips would have to be a nickel based alloy or monolithic SiC. On the other hand, when testing in an inert atmoshere, hot grips may be utilized. The material of the grips can be graphite, which offers adequate strength at high temperatures in a nonoxidizing environment.

The gripping fixtures require some form of alignment device. The hydraulic unit used at ORNL is recommended. Also, careful alignment of the specimen is required when initially loading it into the grips.

silicon carbide inserts should be placed between the specimen and the grips to minimize possible failure of the specimen under the grips. In addition, to promote failure within the gage section, it is recommended that the specimen be necked down through the width. Finite element analysis should be utilized in optimizing the specimen shape before conducting the actual high

temperature tensile tests.

To raise the temperature of the specimen, the use of a resistance furnace is recommended. The furnace can be the split type which makes available easy access to the specimen and the grips. Two different furnaces should be used; one for testing in air and the other for testing in an inert atmosphere. Both furnaces would require at least two windows, one on either side of the furnace. These windows would be used for the optical strain measuring device. Another window might be added for use with an optical pyrometer. It is also recommended that the furnaces be sealed to reduce the turbulence within the chamber. The heating elements should consist of Super Kanthal or silicon carbide for 
the in air testing and tungsten elements for testing in an inert atmosphere. The size of the furnaces is determined by the specimen and the type of grips which are to be utilized. The furnace which is to be used in the oxidizing atmosphere would have to be sized to accommodate a 130 millimeter ( 5 inch) specimen with a 25 millimeter ( 1 inch) gage section and cooled grips. The grips are to be located outside of the furnace. The furnace which is to be used in an inert atmosphere has to accomodate a specimen with hot grips. The grips should be located within the furnace.

The recommended technique for tracking strain is the use of an electro-optical strain measuring device. The zimmer Electro-Optical Extensometer offers optimum performance. This electro-optical strain measuring device requires two windows located on diagnally opposite sides of the furnace.

For the initial testing, it is recommended that a platinum-rhodium thermocouple be used for measuring the temperature of the specimen gage section. Once other problems have been minimized or eliminated the use of an optical pyrometer is suggested. The use of optical pyrometers requires some knowledge of the specimen emissivity at the test temperatures. As a result, determining the emissivity and how it changes during a test can be very time consuming. Once the emissivity of the specimen has been determined at the test temperatures, the application of the ratio pyrometer is recommended.

\section{REFERENCES}

1. Mandell, J.F., Grande, D.H., and Dannemann, K.A., "High Temperature Testing of Glass/Ceramic Matrix Composites," ASTM Symposium, "Test Methods and Design Allowables for Fibrous Composites: Second Symposium," Phoenix, Az., Nov. 3-4, 1986.

2. Mandell, J.F., Grande, D.H., and Jacobs, J., "Tensile Behavoir of Glass/Ceramic Composite Materials at Elevated Temperatures," Gas Turbine Conference and Exhibit, May 31-June 4, 1987, ASME paper no. $87 \mathrm{GT} 75$.

3. Grande, D.H., "Testing and Properties of High Temperature Glass-Ceramic Matrix Composites," Ph.D. Thesis, Massachusetts Institute of Technology, 1987. 
4. Mah, T., et. al., "High Temperature Mechanical Behavoir of Fiber Reinforced Glass Ceramic Matrix Composites," Communication of the American Ceramic Society, sep 1985 .

5. Mah, T., et. al., "Recent Developments in Fiber Reinforced High Temperature Ceramic Composites," Ceramic Bulletin, V66, N2, Feb 1987, pp. 304-308.

6. Personal communication with Noel E. Ashbaugh, University of Dayton Research Institute, Automated Material Characterization Group, Jun. 5, 1987.

7. Personal communication with David A. Utah, General Electric Company, Cincinnati, OH, August 21, 1987.

8. Larsen, D.C., et. al., "Test Methodology for Ceramic Fiber Composites: Results for Sic/LAS, SiC/SiC, and C/SiC Composites," In NASA, Langley Research Center Metal Matrix, Carbon, and Ceramic Matrix Composites 1985.

9. Jamet, J.F., Lewis, D., and Luh, E. Y., "Characterization of Mechanical Behavoir and Fractogaphic Observations on Compglass SiC/LAS Composites," Ceramic Engineering and Science Proceedings, V5, Jul-Aug, 1984, pp. 625-642

10. Personal communication with H.S. Starrett, Southern Research Institute, Birmingham, Al., Aug. 5, 1987.

11. Lui, K.C., and Brinkman, C.R., "Tensile Cyclic Fatigue of Structural Ceramics," Proceedings of the Twenty-Third Automotive Technology Development Contractors' Coordination Meeting," Dearborn, Mi., Oct 21 to 24,1985 .

12. Starrett, H.S., "High Temperature Tensile Testing in Air," Inter Agency Planning Group Meeting at the Institute for Defense Analysis, Alexandria, Virginia, Nov 12, 1986.

13. Sumner, G.,"Heating Methods and Grips," Techniques for High Temperature Fatigue Testing. London and New York: Elsevier Applied Science Publishers, 1985, pp. 71-96.

14. Huddleston, R.,"Oak Ridge Presentation," $\underline{\text { High }}$ 
Temperature Testing of Carbon-Carbon and Ceramic Matrix Composites., ed. T. F. Kearns. Institute for Defense Analyses, IDA Memorandum Report M-278, Dec 1986.

15. Halbach, C.R., Page, R.J., Arthur, P.D., " $2200^{\circ} \mathrm{C}$ Oxidizing Atmosphere Furnace for Space Manufacturing," AIAA 12th Aerospace Sciences Meeting, Washington, D.C., Jan 30 to Feb 1, 1974, AIAA Paper No. 74-154.

16. Lewis, D., Bulik, C., and Shadwell, D., "Standardized Testing of Refractory Matrix/Ceramic Fiber Composites," Ceramic Engineering and Science Proceedings, V6, Jul-Aug, 1985, pp. 507-517.

17. Personal communication with Dan Carroll, National Bureau of Standards, Gaithersburg, Maryland, September 1, 1987 .

18. Davies, C.K.I., and Sinha Ray, S.K.,"A Simple Apparatus for Carrying out Tensile Creep Tests on Brittle Materials Up To Temperatures of $1750^{\circ} \mathrm{C}, "$ Journal of Physics E: Scientific Instruments, V4, 1971.

19. Matsusue, K., Fujisawa, Y., and Takahara, K., "Tensile Test of Pressureless Sintered Silicon Nitride at Elevated Temperatures," NASA Technical Memorandum 77777 .

20. Bhatt, R.T.,"Mechanical Properties of SiC Fiber-Reinforced Reaction-Bonded $\mathrm{Si}_{3} \mathrm{~N}_{4}$ Composites," NASA Technical Memorandum 87085.

21. Gyekenyesi, J.Z., and Hemann, J.H.,"optical strain Measuring Techniques for High Temperature Tensile Testing," NASA Contractor Report 179637.

22. Hobart, H.F., "The NASA Lewis Strain Gauge Laboratory - An Update," Turbine Engine Hot Section Technology 1986, NASA Conference Publication 2444 .

23. Bayer, M., and Cloud, G. "Moire to $1370^{\circ} \mathrm{C}$," Proceedings of the 1986 SEM Spring Conference on Experimental Mechanics, New Orleans, LA, Jun. 8-13, 1986 . 
24. Jenkins, M.G.,"Ceramic Crack Growth Resistance Determination Utilizing Laser Interferometry," Ph.D. Thesis, The University of Washington, 1987.

25. Pears, C.D., et. al., "Test Methods for High Temperature Materials Characterization," Technical Report AFML-TR-79-4002

26. Mecholsky, J.J.,"Evaluation of Mechanical Property Testing Methods for Ceramic Matrix Composites," Ceramic Bulletin, V65, N2, 1986.

27. Wakai, F., et. al., "Tensile Creep Test of Hot Pressed $\mathrm{Si}_{3} \mathrm{~N}_{4}, "$ Presented at the International Symposium on Ceramic Components for Engines, Hakone, Japan, Oct $17-21,1983$.

28. Wiederhorn, S.M., et. al., "Standard Tensile Test Development," Proceedings of the Twenty-Forth Automotive Technology Development Contractors' Coordination Meeting P-197, Dearborn, Michagan, Oct 27-30, 1986.

29. "1100 Series Measurement and Control System/ Laser Dimension Sensor Model 1104", Zygo Corp., Middlefield, CT 06455-0448.

30. Govila, R.K.,"High Temperature Uniaxial Tensile Stress Rupture Strength of Sintered Alpha SiC," Journal of Materials Science, V18, 1983.

31. Rozak, G.A.,"Stress Rupture Behavoir of Silicon Carbide Coated, Low Modulus Carbon/Carbon Composite," Master of Science Thesis, Case Western Reserve University, 1987.

32. Jaroszynski, W.S., "Measuring Temperatures Radiometrically," Machine Design, July 9, 1987.

33. "Radiation Pyrometry, Theory and Practice," Capintec Instruments Inc., Montvale, NJ 138630.

34. Tenney III, A.S., "Red Hot.... and Hotter," Mechanical Engineering, V108, N10, Oct 1986. 


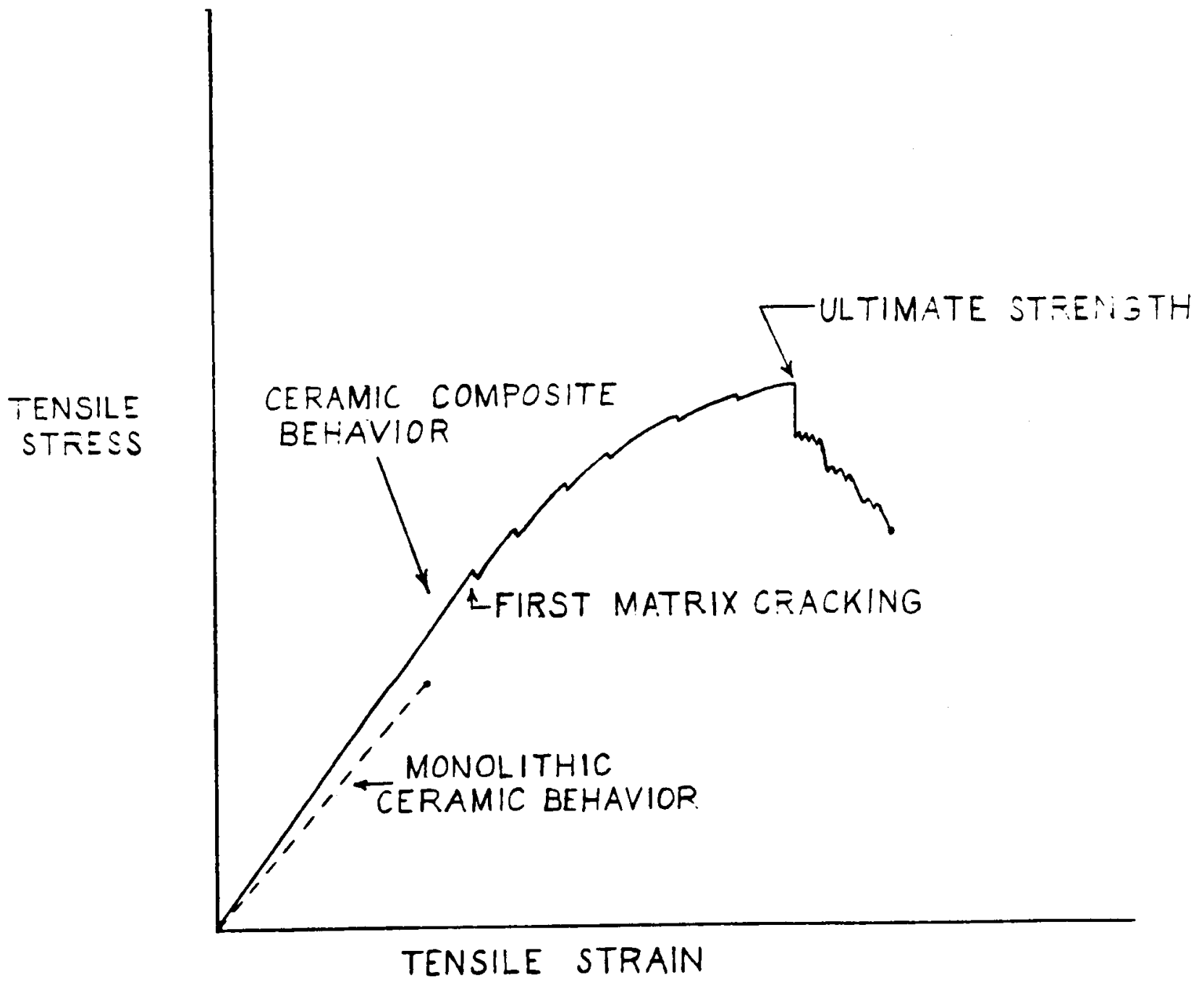

Fig. 1 Idealized stress-strain curve for fiber reinforced ceramic composites. 

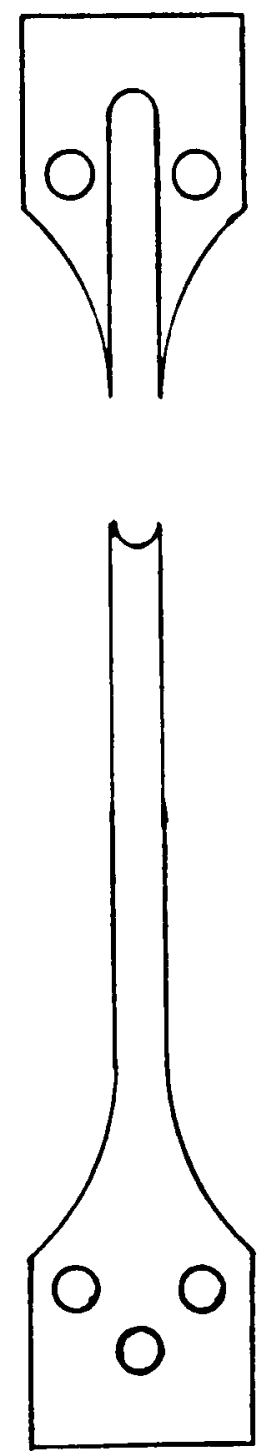

Fig. 2 Shear failure of longitudinal fiber reinforced ceramic specimen using pin grips. 
1. hydraulic piston assembly

2. fluid channel

3. fill port

4. oil chamber

5. O-ring seal

6. piston

7. ball-bearing bushing

8. snap ring

9. cover

10. metal pull rod

11. fastener

12. grooved flat ring

13. cooling channel

14. tapered split collar

15. metal plug

16. specimen
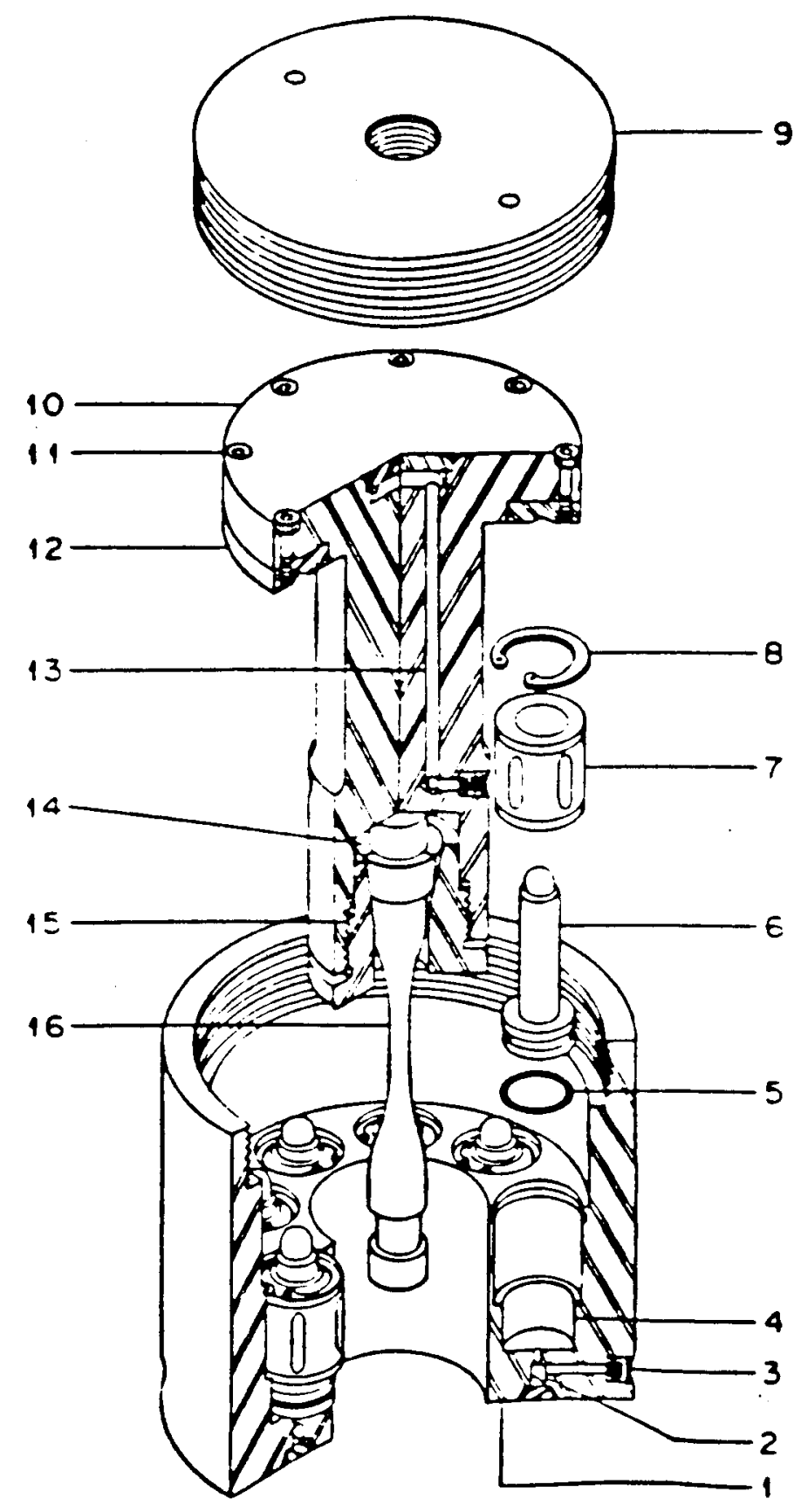

Fig. 3 Cutaway view of ORNL self-alligning grip system. 


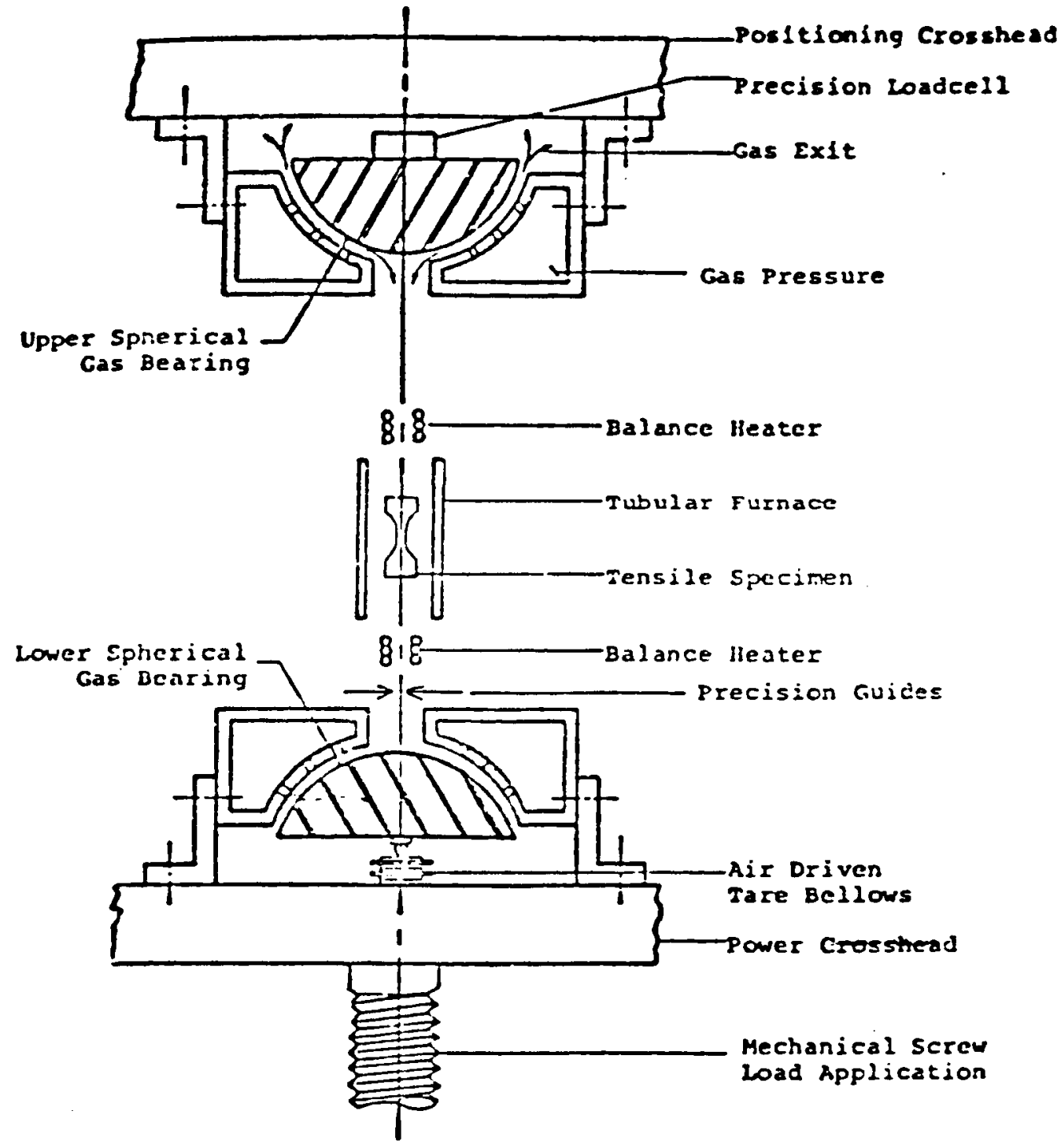

Fig. 4 Schematic arrangement of gas bearing universals, specimen, and load train. 


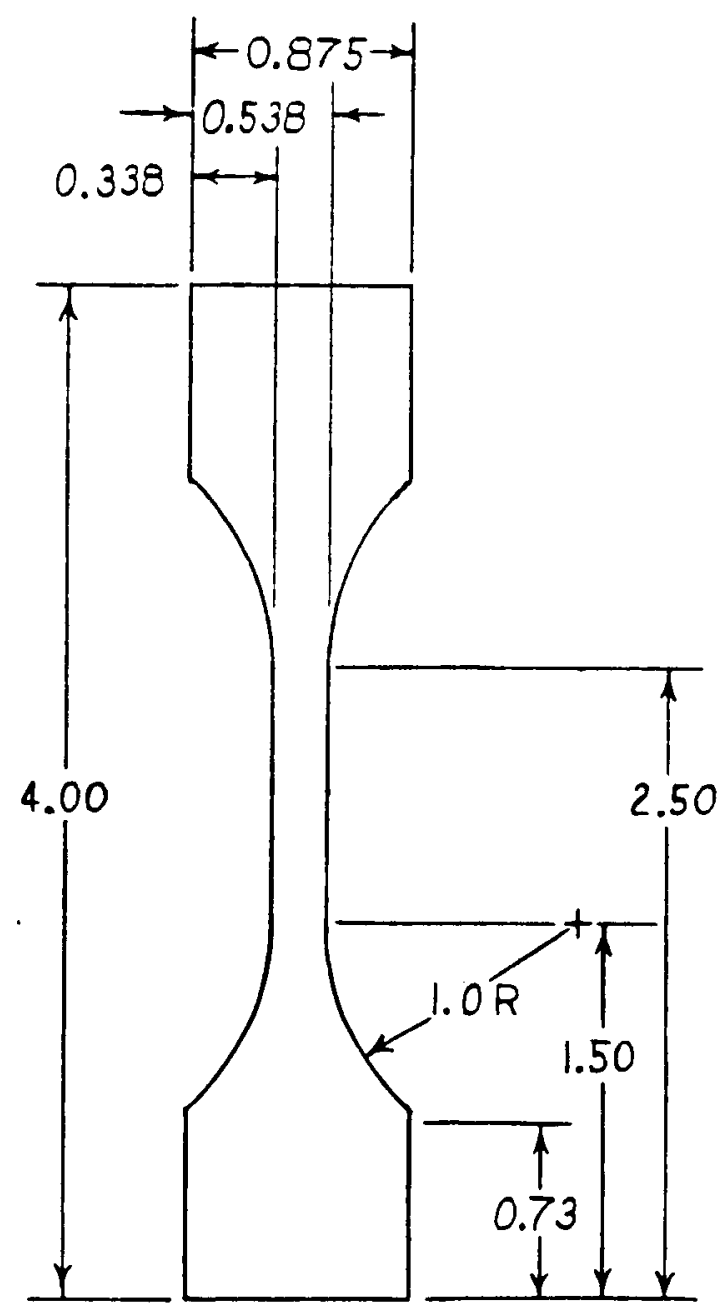

ALL DIMENSIONS IN INCHES

Fig. 5 Ceramic composite specimen configuration for high temperature tensile testing with a friction gripping system. 

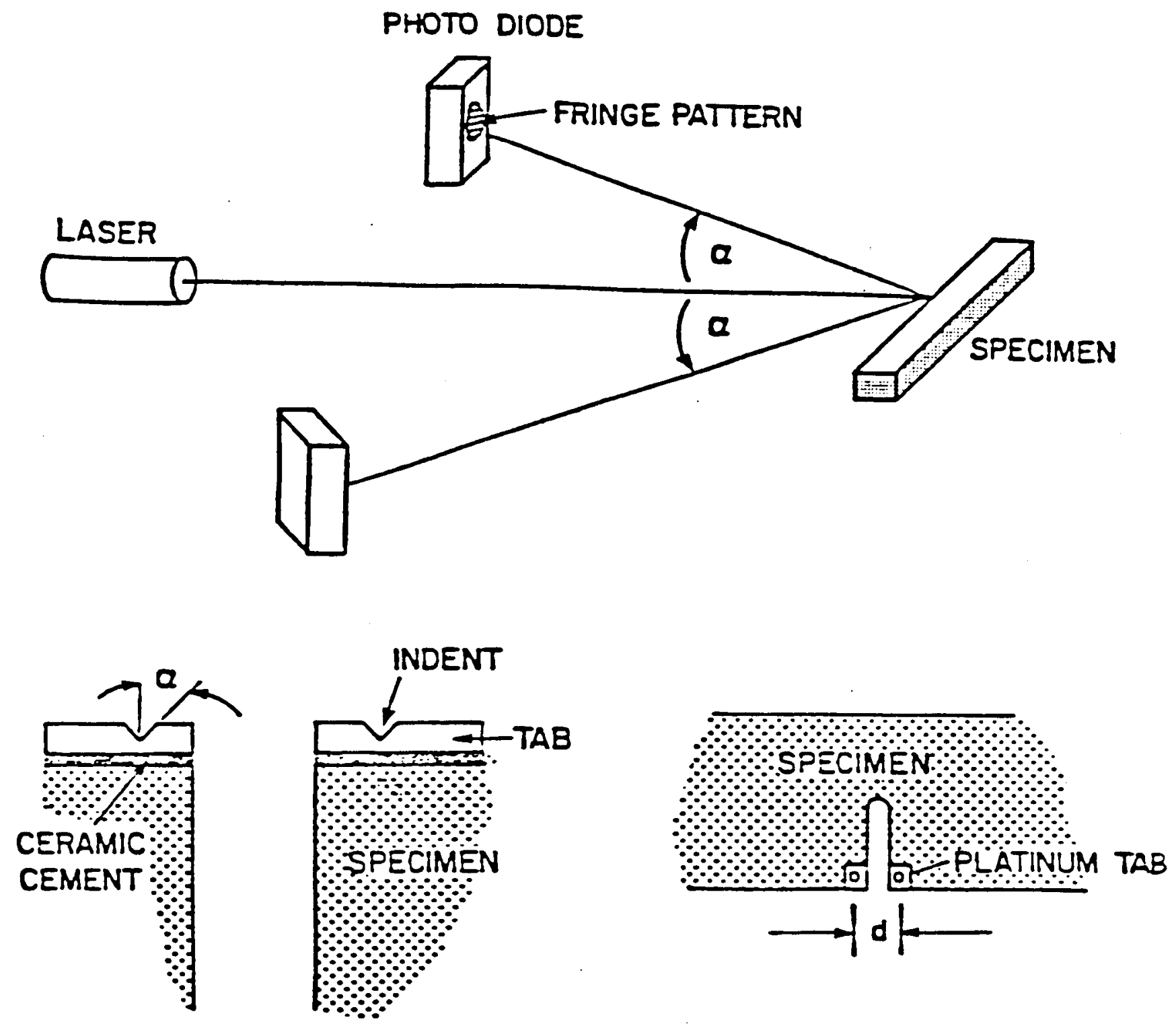

$$
\Delta d=\frac{\Delta m_{1}+\Delta m_{2}}{2} \frac{\lambda}{\sin \alpha}
$$

Fig. 6 Schematic of the Laser Interferometric Strain Gage. 


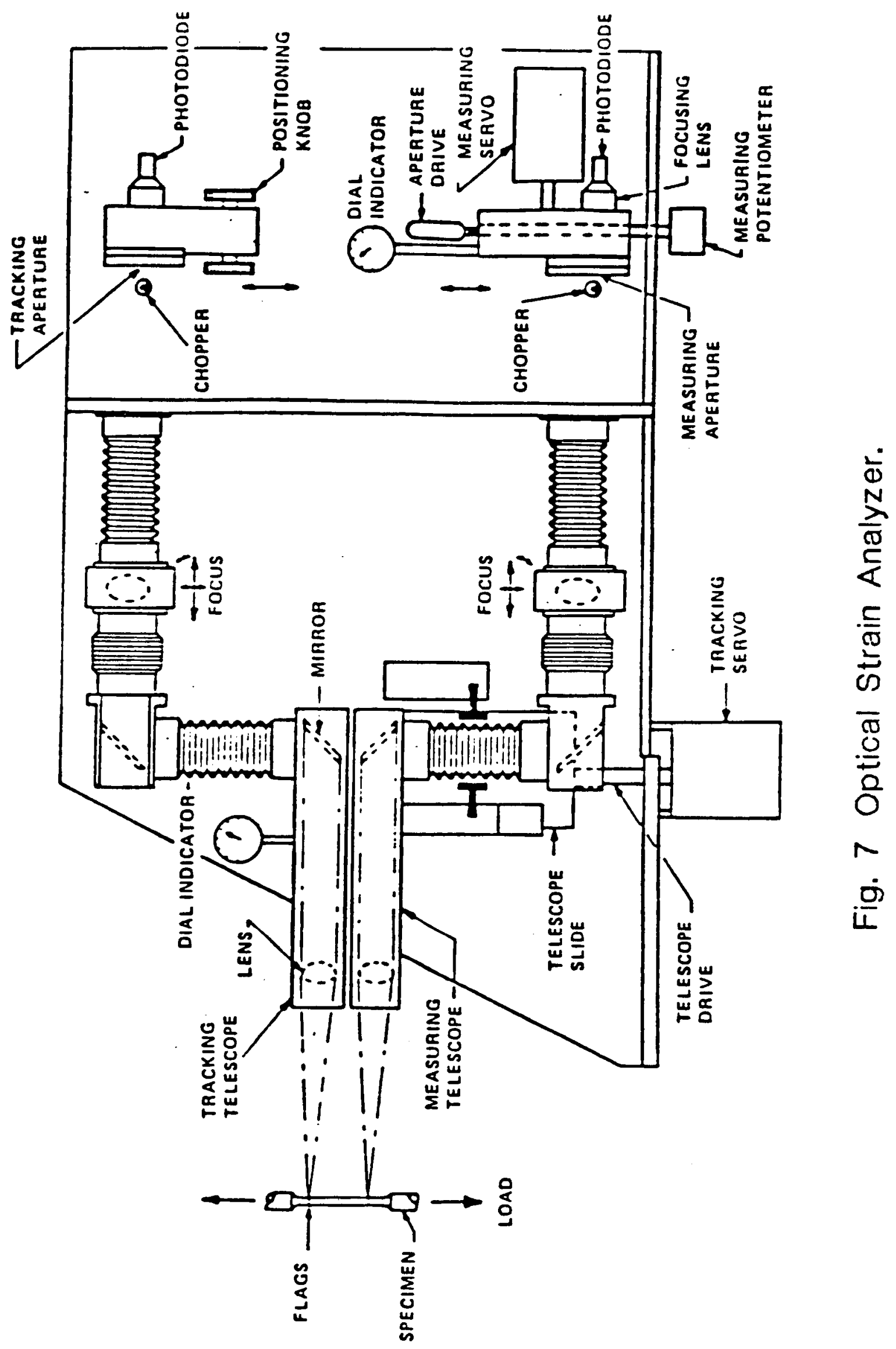




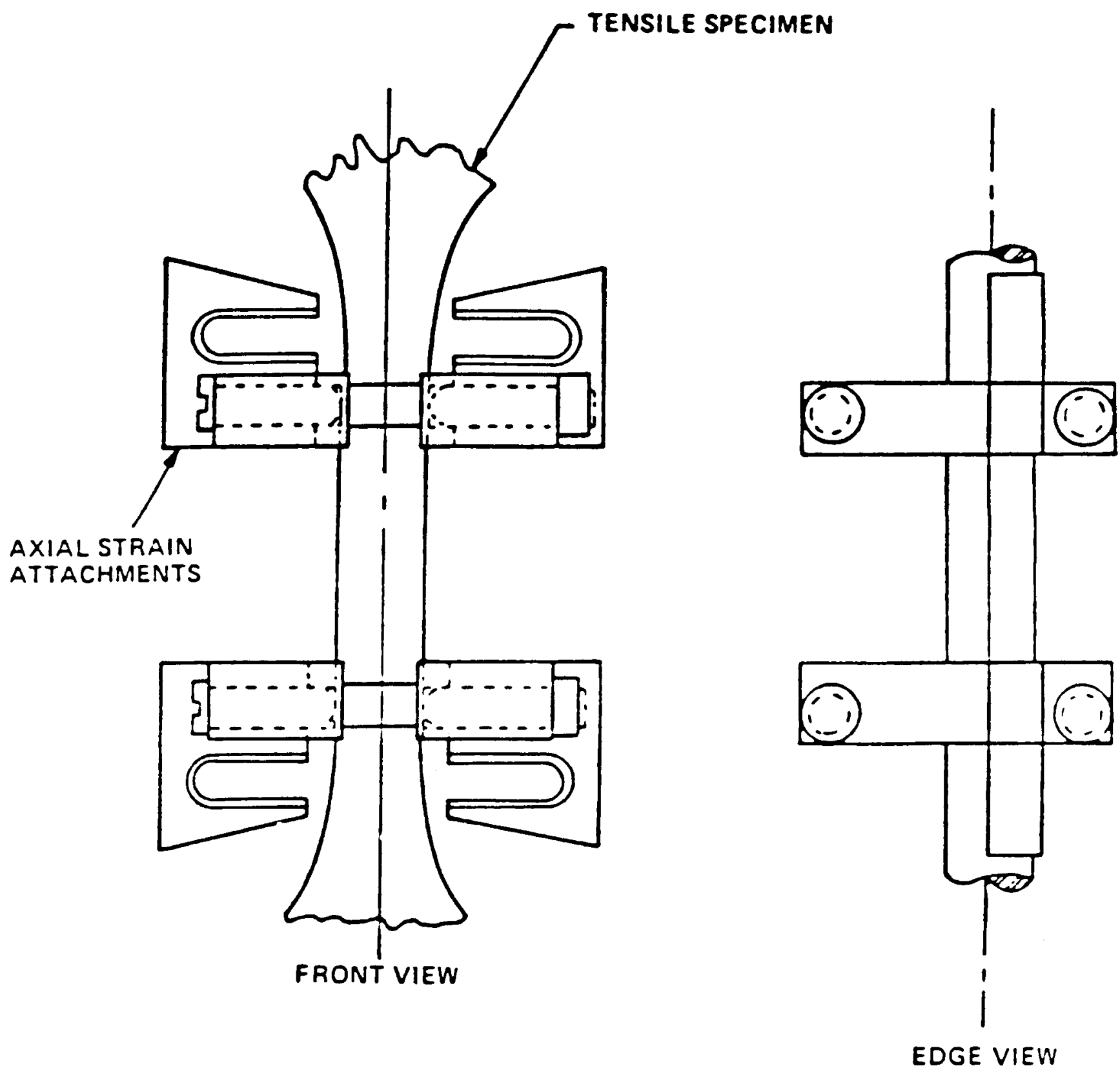

Fig. 8 Targets attached to tensile specimen for use with the Optical Strain Analyzer. 


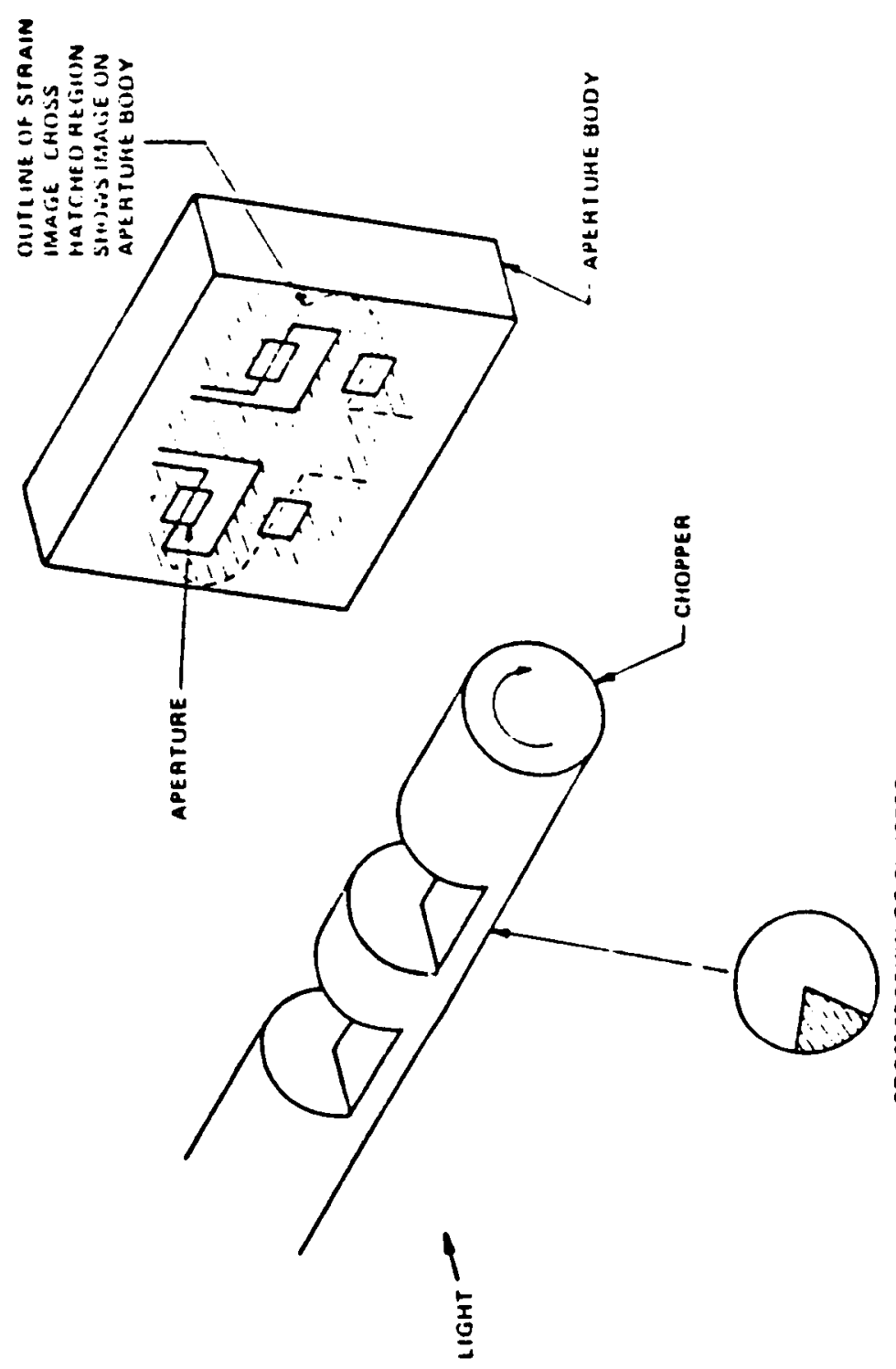

$\frac{\overline{8}}{\frac{0}{0}}$

돈

4

$\infty$

(1)

$\frac{3}{2}$

$\frac{2}{6}$

$\stackrel{\infty}{\Phi}$

$\frac{0}{6}$

\begin{tabular}{l}
$\frac{1}{0}$ \\
$\frac{0}{2}$ \\
$\frac{1}{0}$ \\
\hline 0
\end{tabular}

$\stackrel{9}{\ddagger}$

$\frac{\text { D }}{3}$

这

N

음

息

os

i் 
a)

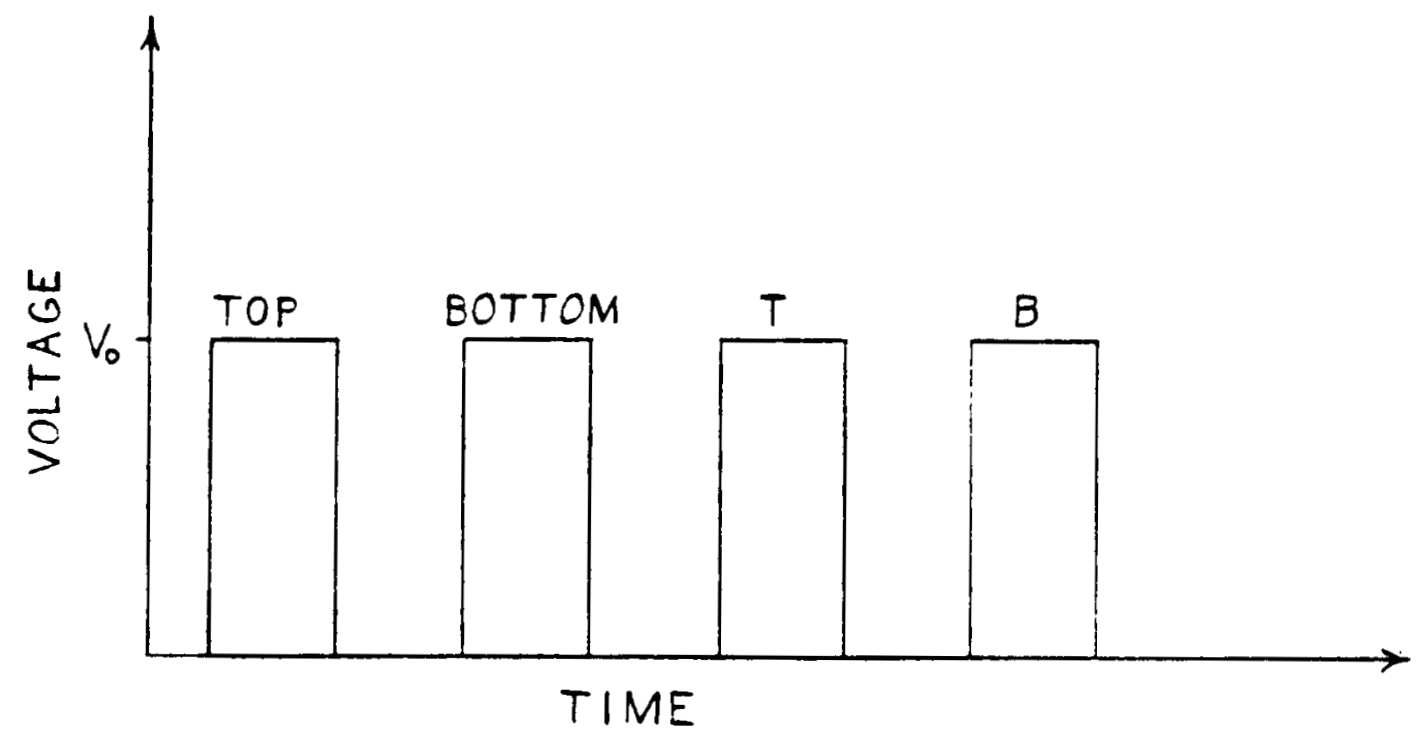

b)

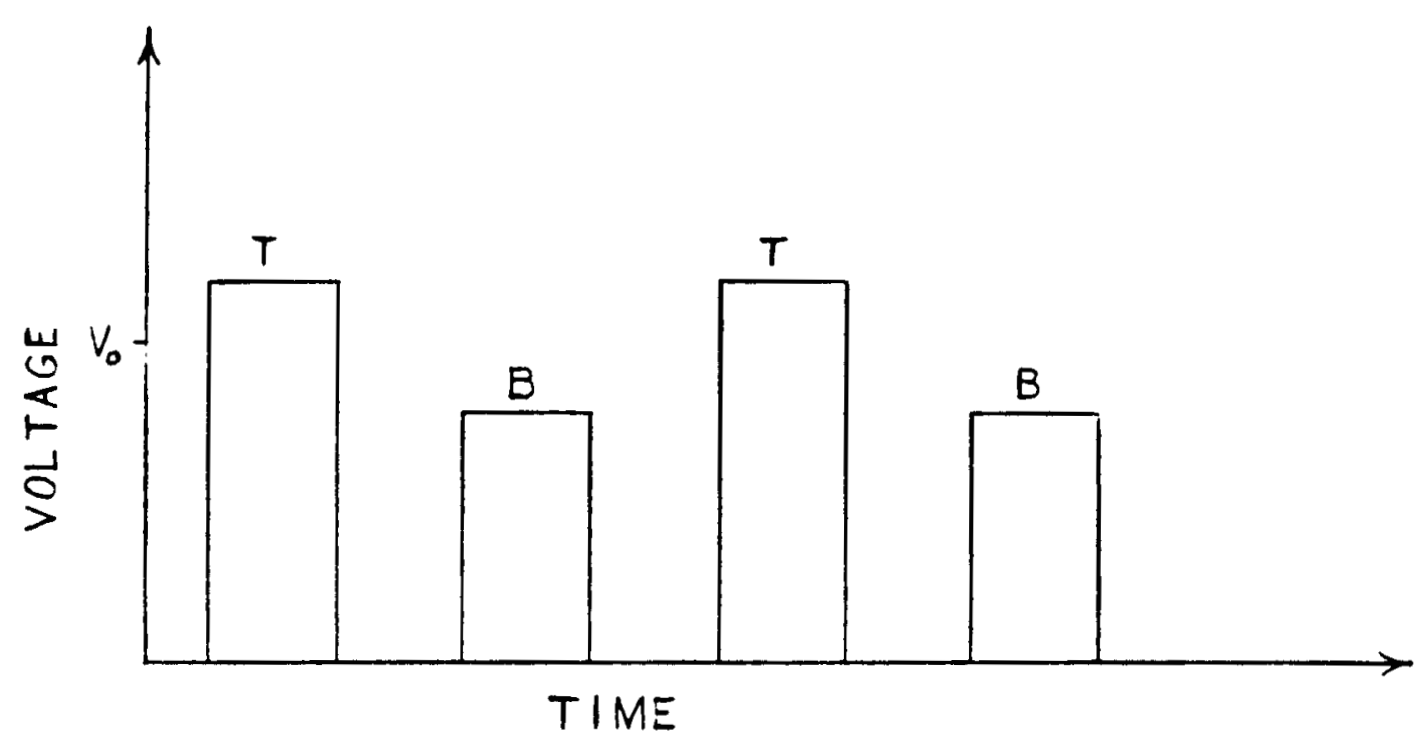

Fig. 10 Output for the Optical Strain Analyzer:

a) Null point before deformation of the specimen.

b) After deformation of the specimen. 


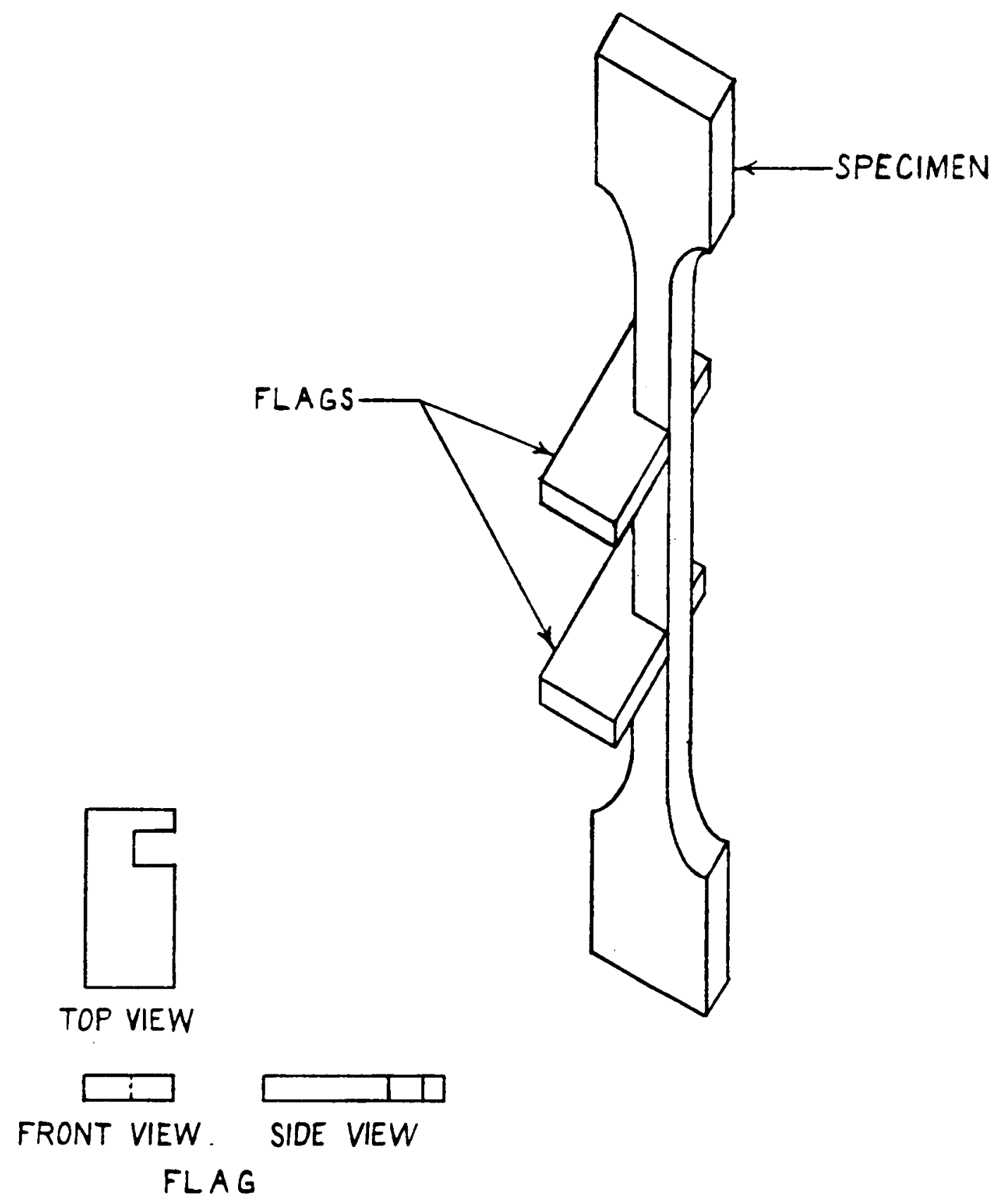

Fig. 11 Flags attached to tensile specimen for use with the Zimmer Electro-Optical Extensometer. 


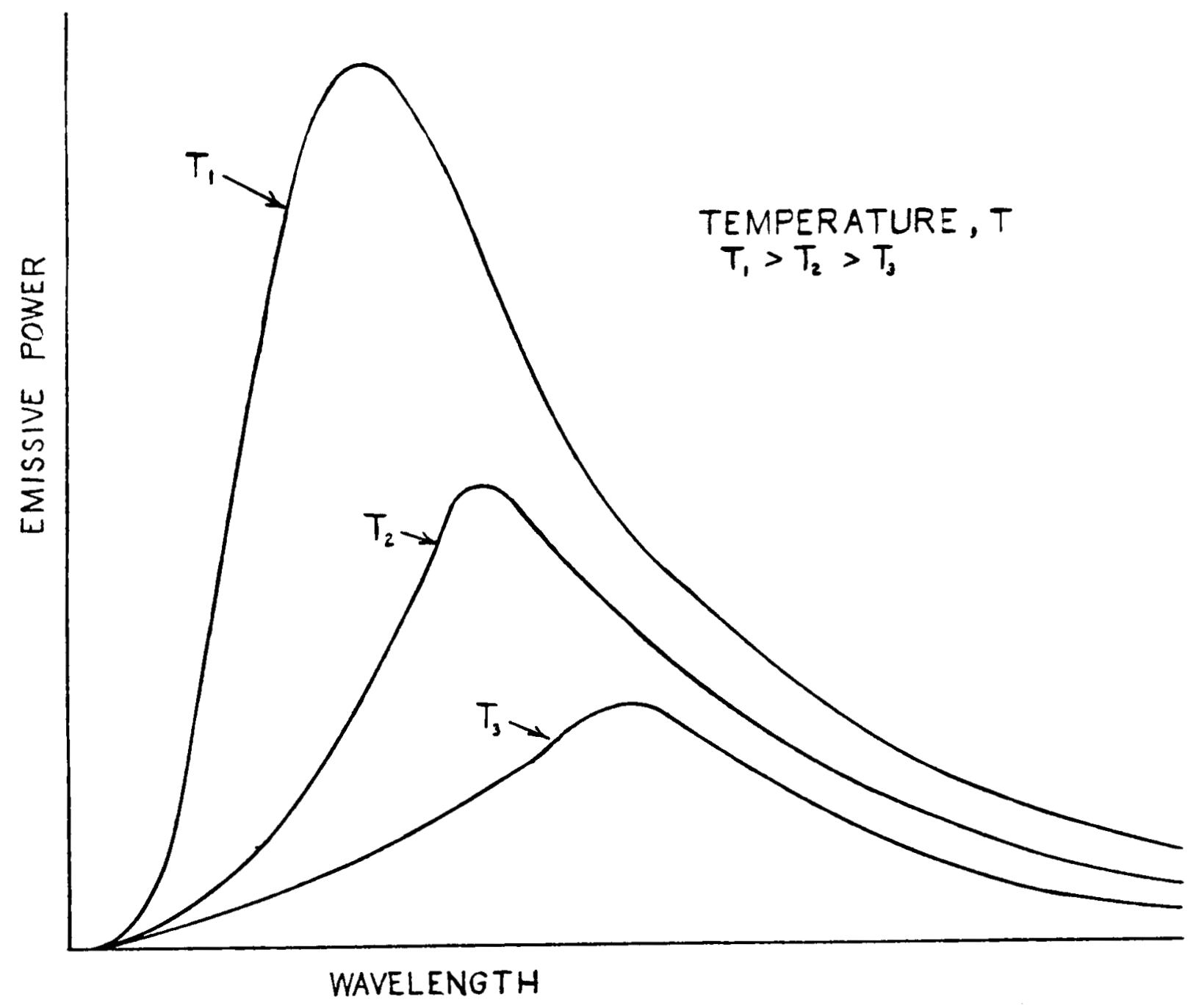

Fig. 12 Emissive power of a body as a function of wavelength and temperature. 
$\epsilon_{A}=E M I S S I V I T Y$ AS A FUNCTION OF WAVELENGTH TEMPERATURE $T=$ CONSTANT

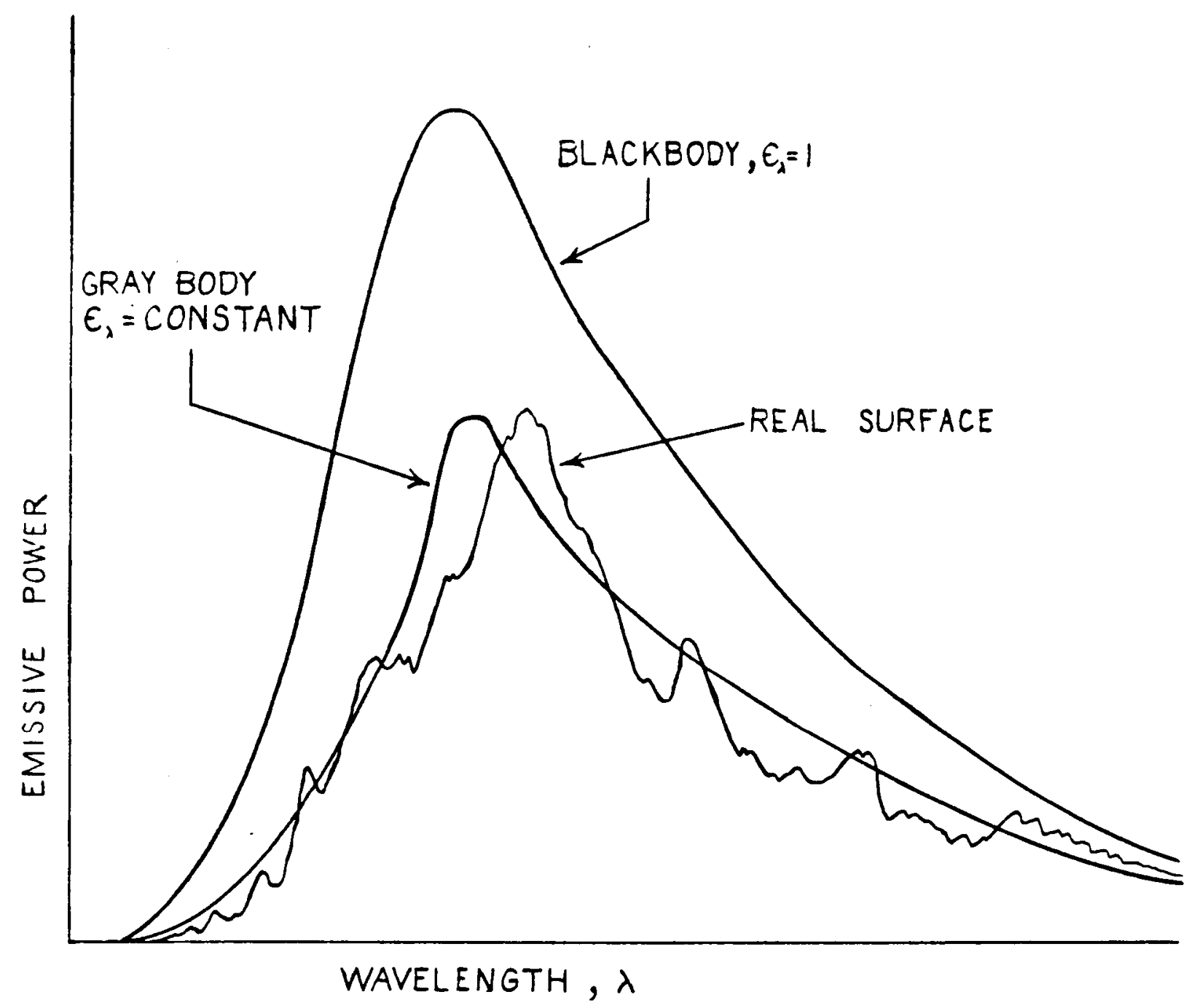

Fig. 13 Emissive power of various bodies as a function of wavelength. 


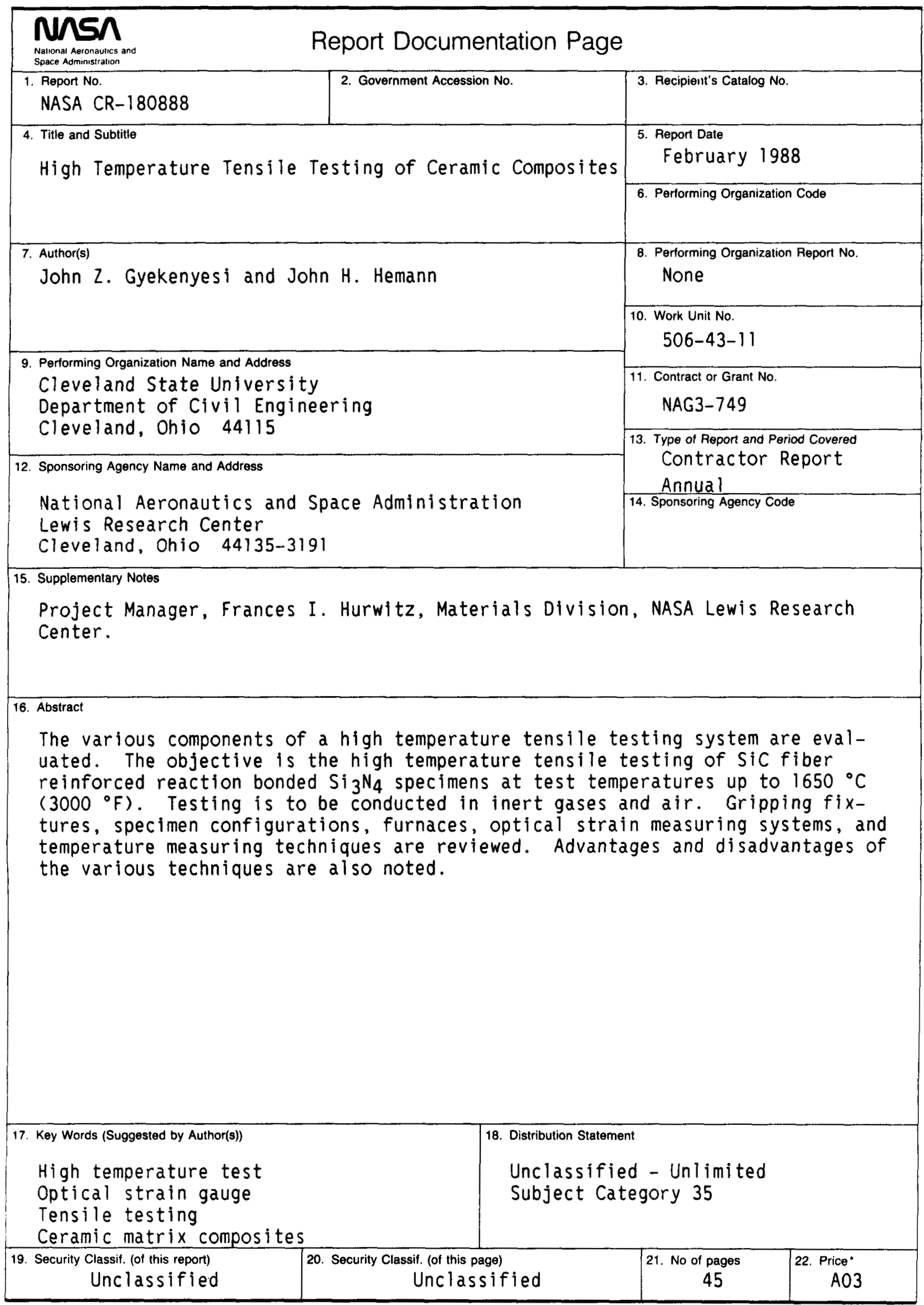

